Prepared in cooperation with the Office of Emergency Management, U.S. Department of the Interior

\title{
Assessing Hazards and Risks at the Department of the Interior -A Workshop Report
}
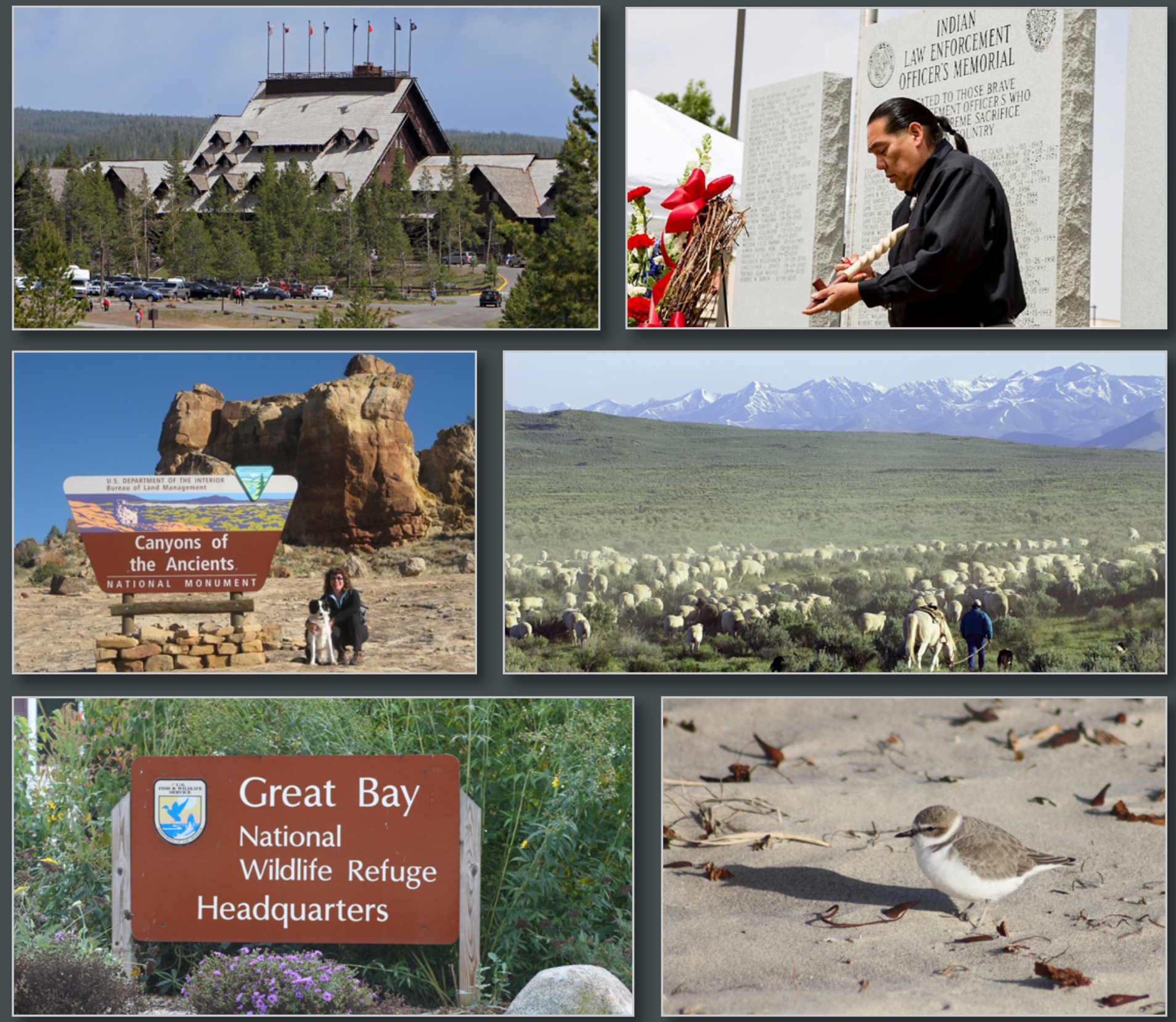

Circular 1453

U.S. Department of the Interior

U.S. Geological Survey 

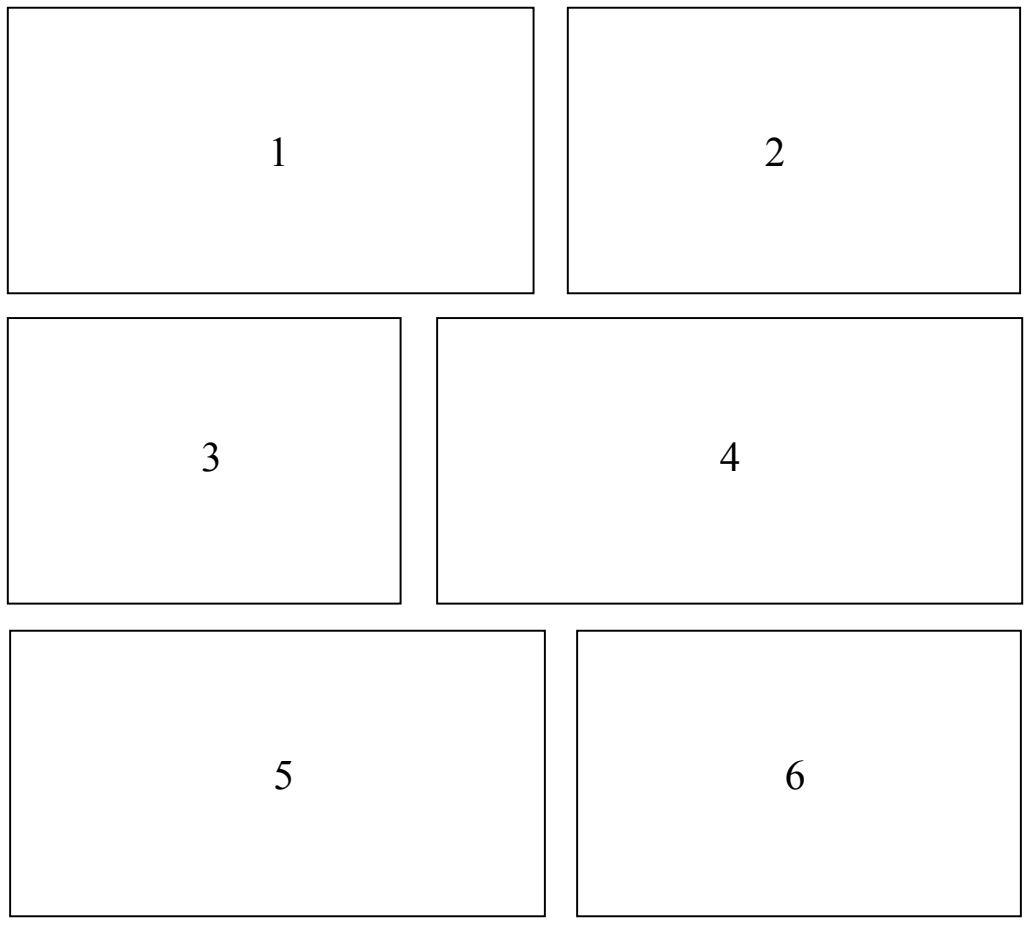

Cover. Compilation of various resources and activities typically found on lands of, or managed by, the Department of the Interior, such as tourists and facilities at Yellowstone National Park (image 1), ranching (image 4), and the Western Snowy Plover (image 6).

Sources:

National Park Service (image 1)

Bureau of Indian Affairs, Office of Justice Services (image 2)

Bureau of Land Management (images 3 and 4)

U.S. Fish and Wildlife Service (images 5)

California State Parks, photo taken by Brooke Sheridan (image 6) 


\section{Assessing Hazards and Risks at the Department of the Interior-A Workshop Report}

By Nathan Wood, Alice Pennaz, Kristin Ludwig, Jeanne Jones, Kevin Henry, Jason Sherba, Peter Ng, Jason Marineau, and John Juskie

Prepared in cooperation with the Office of Emergency Management, U.S. Department of the Interior

Circular 1453 


\title{
U.S. Department of the Interior \\ DAVID BERNHARDT, Acting Secretary
}

\author{
U.S. Geological Survey \\ James F. Reilly II, Director
}

U.S. Geological Survey, Reston, Virginia: 2019

For more information on the USGS - the Federal source for science about the Earth, its natural and living resources, natural hazards, and the environment-visit https://www.usgs.gov or call 1-888-ASK-USGS.

For an overview of USGS information products, including maps, imagery, and publications,

visit https://store.usgs.gov.

Any use of trade, firm, or product names is for descriptive purposes only and does not imply endorsement by the U.S. Government.

Although this information product, for the most part, is in the public domain, it also may contain copyrighted materials as noted in the text. Permission to reproduce copyrighted items must be secured from the copyright owner.

Suggested citation:

Wood, N., Pennaz, A., Ludwig, K., Jones, J., Henry, K, Sherba, J., Ng, P., Marineau, J., and Juskie, J., 2019, Assessing hazards and risks at the Department of the Interior-A workshop report: U.S. Geological Survey Circular 1453, 42 p., https://doi.org/10.3133/cir1453.

ISSN 2330-5703 (online) 


\section{Contents}

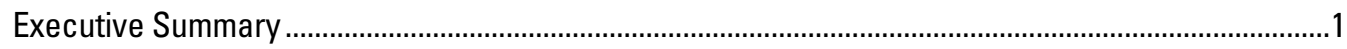

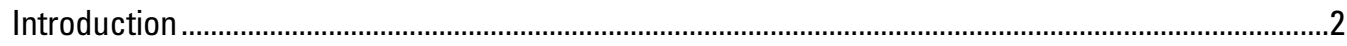

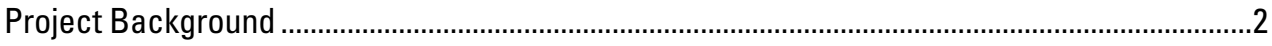

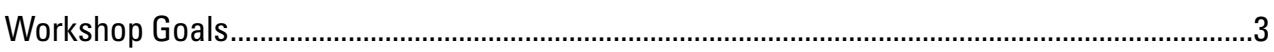

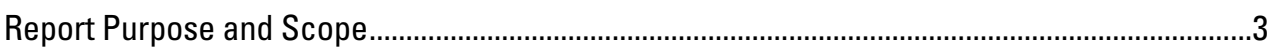

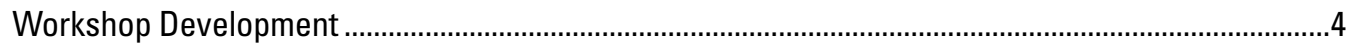

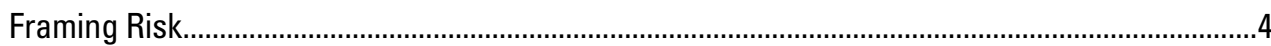

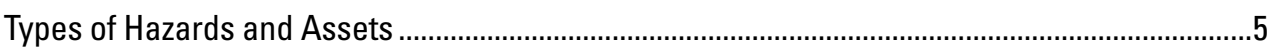

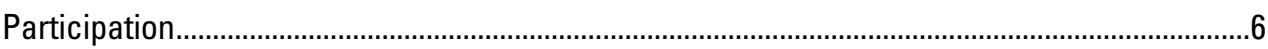

Format

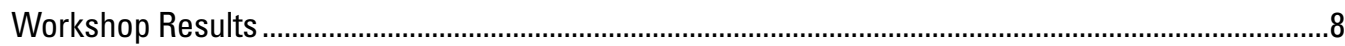

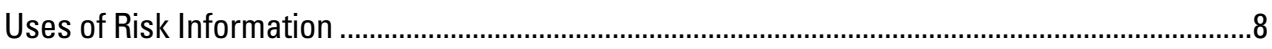

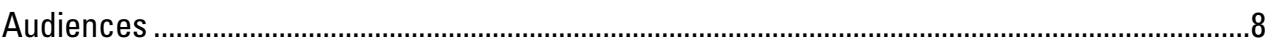

Identifying and Prioritizing Asset Data .....................................................................................

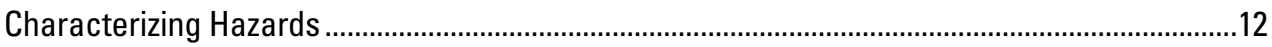

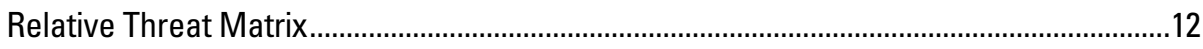

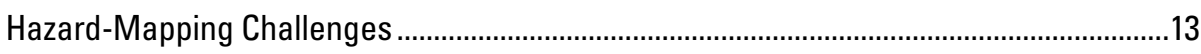

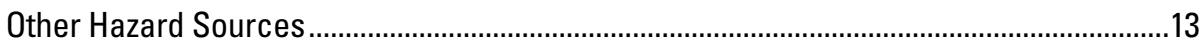

Additional Hazard Sub-Categories ...................................................................................

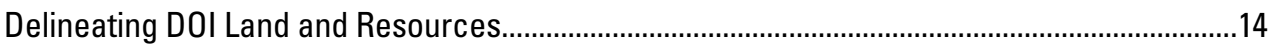

Hazards Exposure Overlays.................................................................................................16

Scale of Relevant Risk Information .......................................................................................16

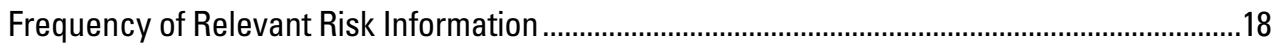

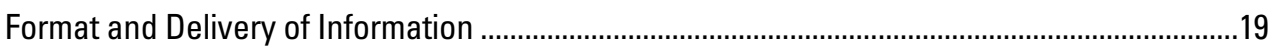

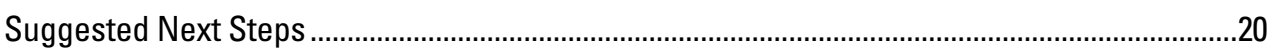

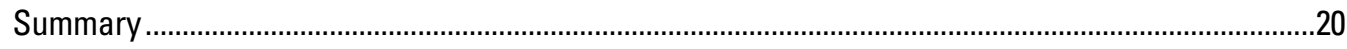

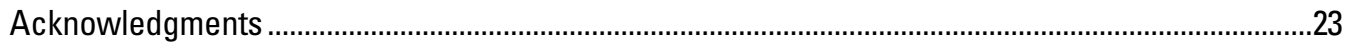

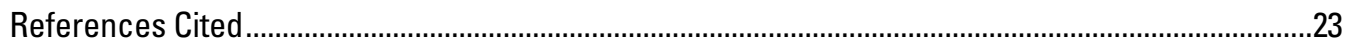

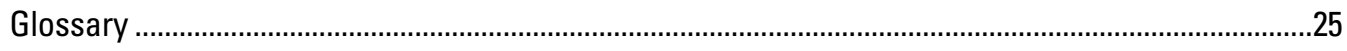

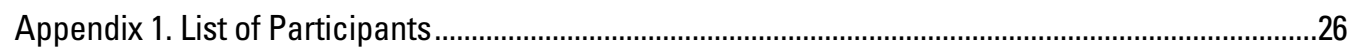

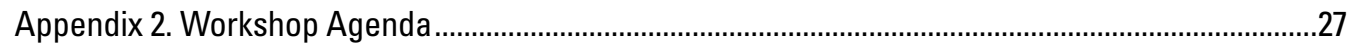

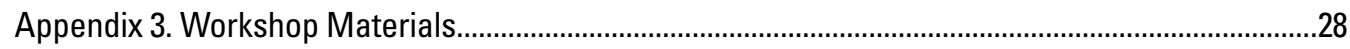

Appendix 4. Examples of Use Case Statements ..............................................................................34

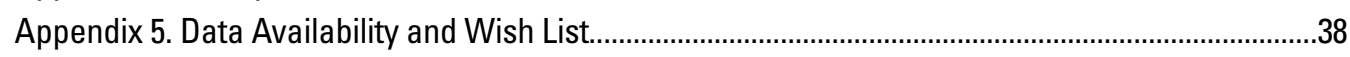

Appendix 6. Potential Hazard Categories in Relative Threat Matrix ..................................................42 


\section{Figures}

1. Spectrum of approaches to characterize societal risk from hazards

2. Seven hazard types approved by the Senior Executive Emergency Management Council ..... 5

3. Categories of assets used at the February 2018 workshop......................................................... 6

4. Photograph of many of the workshop participants ................................................................. 7

5. Photograph of table discussions during the workshop ............................................................ 7

6. Participant responses on positive aspects of the workshop format, and areas for improvement in future workshops .........................................................................................

7. Types of decisions being made by DOI Bureaus and Offices, organized by asset of concern and decision type.................................................................................................................

8. Types of information currently being used to make decisions/plans..........................................

9. Participant responses on additional data needed to make decisions or strategic planning .... 9

10. Photograph of a workshop participant discussing potential audiences for risk data................. 9

11. Types of audiences that would benefit from DOI risk information and products ...................... 10

12. Photograph of a table discussion on data "wish lists" during the workshop ............................ 10

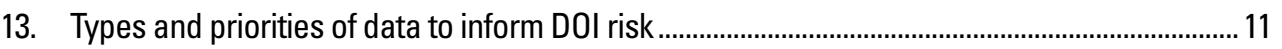

14. Workshop participant desire for range of classes other than high for a variety of hazards ... 13

15. Workshop participant desire for data on historic occurrences of various hazards.................. 13

16. Workshop participant desire for further classification of a hazard.......................................... 14

17. Map of federally managed lands in the Protected Areas Database of the United States....... 15

18. Desired hazard-asset overlays based on various hazards and asset combinations ................ 17

19. Assets information desired by workshop participants....................................................... 17

20. Desired scale of risk information and products that is most relevant to DOI planning............. 18

21. Desired frequency of risk information and products that is most relevant to DOI planning, including examples provided by participants. ........................................................................... 18

22. Examples of approaches to visualize and share risk information............................................. 19

23. Desired characteristics of information and product delivery in terms of features and format

24. An example of a hand-drawn sketch by a workshop participant of a potential data dashboard for providing customizable risk information ........................................................... 21

25. Responses on short-term priorities, long-term goals, and general project thoughts ............... 21

26. Overview of SHIRA-related processes and products desired by workshop participants........22

3.1. Worksheet for "Information You Use and How You Use It" session...........................................29

3.2. Worksheet \#1 for "Hazard Characteristics and Considerations" session ...................................30

3.3. Worksheet \#2 for "Hazard Characteristics and Considerations" session .................................... 31

3.4. Worksheet \#3 for "Hazard Characteristics and Considerations" session ..................................... 32

3.5. Worksheet for "Information Delivery: Frequency, Geographic Scale, and Comparisons"

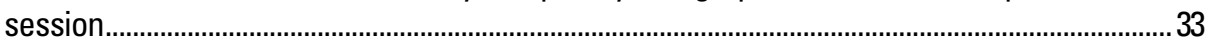

6.1. Hazard categories for the Department of the Interior in relative threat matrix.......................... 42 


\section{Abbreviations}

\begin{tabular}{ll} 
BIA & Bureau of Indian Affairs \\
BIO & Business Integration Office \\
BLM & Bureau of Land Management \\
BOEM & Bureau of Ocean and Energy Management \\
BSEE & Bureau of Safety and Environmental Enforcement \\
DOI & U.S. Department of the Interior \\
EMC & Emergency Management Council \\
FEMA & Federal Emergency Management Agency \\
FWS & U.S. Fish and Wildlife Service \\
IBC & Interior Business Center \\
NLE & National Level Exercise \\
NPS & National Park Service \\
OCIO & Office of the Chief Information Officer \\
OEM & Office of Emergency Management \\
OEPC & Office of Environmental Policy and Compliance \\
OLES & Office of Law Enforcement and Security \\
PPA & Office of Policy Analysis \\
OWF & Office of Wildland Fire \\
PAM & Office of Acquisition and Property Management \\
Reclamation & Bureau of Reclamation \\
SE-EMC & Senior Executive Emergency Management Council \\
SHIRA & Strategic Hazard Identification and Risk Assessment \\
SNRA & Strategic National Risk Assessment \\
USDA & U.S. Department of Agriculture \\
USFS & U.S. Forest Service \\
USGS & U.S. Geological Survey \\
USPP & U.S. Park Police \\
\hline
\end{tabular}





\title{
Assessing Hazards and Risks at the Department of the Interior-A Workshop Report
}

\author{
By Nathan Wood, Alice Pennaz, Kristin Ludwig, Jeanne Jones, Kevin Henry, Jason Sherba, Peter Ng, \\ Jason Marineau, and John Juskie
}

\section{Executive Summary}

The Strategic Hazard Identification and Risk Assessment of Department of the Interior Resources (SHIRA) Project is a collaboration between the U.S. Geological Survey (USGS) and the Department of the Interior (DOI) Office of Emergency Management (OEM). The SHIRA Project is designed to improve the understanding of risks to DOI assets, resources, and lands from various natural and anthropogenic threats. This risk assessment will help the DOI OEM to determine the need for increased risk-management capabilities and other strategic planning efforts. The assessment involves the collection of existing hazard and asset data from DOI and other Federal sources as well as the creation of new data that visualize spatial variations in hazard exposure of DOI lands, resources, and assets. The SHIRA Project will also provide insight into USGS products that are currently available or could be developed to communicate DOI risks to DOI managers and executives. The long-term goal of this project is a sustained effort to inform these managers and executives of risks posed by a wide range of biological, wildland fire, geophysical, meteorological, technological, and adversarial hazards.

On February 27-28, 2018, the USGS and DOI OEM hosted a workshop to gather input from DOI subject matter experts (SMEs), resource managers, facility managers, emergency managers, and law enforcement personnel. Workshop goals were to (1) determine how DOI Bureaus and Offices use risk information for strategic planning and decision-making; (2) understand what types of information are most useful to DOI Bureaus and Offices; (3) establish what data, information, and products are desired; (4) identify the most effective methods for delivery and visualization; and (5) collect ideas for future project directions. The workshop findings presented in this report will influence the development of risk-information products created by the SHIRA team.

The workshop revealed that participants saw value in riskrelated information not only for emergency management planning but also for other DOI efforts, such as resource and facility management, staff training, and public outreach. Participants noted that risk management occurs at multiple spatial scales and in different contexts across the DOI. Therefore, they requested that risk information be made available through interactive applications that would allow users to customize information by hazard type and thresholds, asset of interest, time period, and spatial scale (from individual facilities to national perspectives). Participants requested that risk information be available in multiple formats, such as tabular data, infographics, and geospatial heat maps for inclusion in web-based mapping applications. In addition to national inventories and composite maps, there was substantial interest in having detailed site-specific information on hazards and the hazard exposure of DOI assets, such as human populations, facilities, and infrastructure. To support risk planning at individual DOI Bureaus and Offices, participants requested that raw geospatial hazard and asset data gathered for the DOI OEM risk assessment be made available via an authoritative and accessible data clearinghouse.

Workshop participants proposed a number of long-term goals for the project. These included creating and maintaining a Department-wide community of practice related to risk analysis, investing in sustained and long-term risk analysis efforts (rather than a one-time analysis), exploring tactical and operational applications (rather than just strategic), and maintaining communication with other agencies to leverage expertise, data, tools, and products. Some first steps towards these long-term goals have already been taken. The workshop seeded a community of practice within the DOI, and the SHIRA Project team has been in communication with other Federal agencies that have similar risk interests. Data compiled for the immediate risk assessment could be made available in a data clearinghouse. Data compiled for the SHIRA project were also used to characterize potential impacts to DOI facilities and employees for a national-level exercise (NLE) in May 2018, which demonstrates the use of risk information for short-term operational assessments, rather than just long-term strategic planning.

To achieve the long-term goals laid out by workshop participants, sustained funding and resource investments need to be identified. For example, an accessible clearinghouse and an interactive web-based application to serve authoritative risk-related data require concerted and sustained efforts to develop, maintain, and update the products to ensure longterm relevance. Similarly, although a community of practice was seeded during the workshop, further investments would be required to expand, nurture, and provide structure over the long term. The transition from a strategic risk assessment to a tactical, operational capability would also require additional funding, resources, and coordination with other Federal groups with similar interests. 
In summary, the workshop achieved the goals of understanding (1) how risk information is used by DOI Bureaus and Offices, (2) the data potentially provided by DOI Bureaus and Offices, and (3) what other data and risk products might be useful. The workshop also helped identify future directions for the SHIRA Project that could be implemented with additional resources. Most importantly, the February 2018 workshop demonstrated that there was broad interest in risk analysis across the DOI which may lead to additional collaborations and opportunities.

\section{Introduction}

\section{Project Background}

The U.S. Department of the Interior (DOI) protects and manages the Nation's natural resources and cultural heritage, provides scientific and other information about those resources, and honors its trust responsibilities or special commitments to American Indians, Alaska Natives, and Insular and affiliated island communities. The DOI has an obligation and a statutory requirement (6 U.S Code $\S 753$ ) to understand the risks posed by various hazards to DOI lands, facilities, people, revenues, and resources. Knowledge of these risks allows the DOI to make informed decisions about how to manage and mitigate risk, respond to incidents, allocate resources, and develop needed plans and capabilities. Detailed risk information is critical to the Department as it revises its All-Hazards Baseline Operational Plan (OEM, 2014) to align with the Presidential Policy Directive for National Preparedness (PPD-8) in accordance with DOI Departmental Manual Part 900 Chapter 1 (DOI, 2012). The DOI All-Hazards Baseline Operations plan provides guidance for how the DOI prepares for and responds to emergencies.

To date, the DOI has never conducted a comprehensive hazards identification and risk assessment to identify which hazards pose the greatest risk to departmental equities and assets. The Federal Emergency Management Agency's (FEMA) Threat and Hazard Identification Risk Assessments (THIRAs) are important tools, but are not the best option for a strategic, national approach for the DOI. The FEMA-developed Strategic National Risk Assessment (SNRA) provides an overarching prioritization of hazards to support national mitigation and preparedness planning, but does not fully encompass the areas, hazards, and assets that are of central concern to DOI. For example, the SNRA primarily focuses on risks to urban areas and stationary populations, whereas many of the DOI's assets are found in rural settings, have highly transient populations, but have few permanent residents. Furthermore, the Department's responsibilities to protect natural and cultural resources are not of primary concern to FEMA; therefore, hazards like wildlife disease or invasive species are not found within the SNRA. In addition, the Stafford Disaster Relief and Emergency Assistance Act of 1988 (42 USC 5121 note) does not apply to Federal lands. Thus, no matter how thorough FEMA risk assessments might be, FEMA is unlikely to include the Federal lands of interest to the DOI in their risk assessments, response and recovery plans, and mitigation efforts.
To address these gaps, the DOI Office of Emergency Management (OEM) approached the U.S. Geological Survey (USGS) in June 2017 to undertake a nation-wide strategic hazard identification and risk assessment that would address the unique concerns of the Department and incorporate departmental lands and resources that often are not included in FEMA assessments. The resulting collaboration between the DOI OEM and USGS on the Strategic Hazard Identification and Risk Assessment of Department of the Interior Resources (SHIRA) Project was envisioned as a two-year effort (fiscal years 2018 and 2019) with the hope that interest from various DOI Bureaus and Offices would lead to further collaborations.

Although the project leverages natural hazards expertise within the USGS, it also includes meteorological, technological and adversarial hazards where technical expertise and data are found elsewhere within the Federal Government. This project provides the USGS with opportunities to forge new partnerships and to further improve its ability to deliver actionable hazard and risk information for decision makers, which are goals outlined in a USGS plan for risk research and applications (Ludwig and others, 2018). The SHIRA Project is designed to:

- Identify a prioritized list of geophysical, meteorological, wildfire, biological, technological, and adversarial hazards, including insights on the geographic distribution and likelihood of occurrence of each hazard within a decadal or human-lifetime scale (if possible);

- Characterize and quantify (where applicable) the hazard exposure of DOI assets including:

- Life-safety and human health of tribal communities, visitors to DOI lands, DOI staff, concessionaires, and inholding communities;

- DOI owned facilities, critical infrastructure, and other physical assets (for example, boats, aircraft, and vehicles);

- DOI managed natural resources of economic value (for example, energy and mineral resources, timber, grazing land, game species, and ecotourism landscapes);

- DOI managed cultural resources including national icons, archeological sites, and historic structures; and

- Vulnerable environmental resources (for example, threatened and endangered species range/habitat).

- Acquire, develop, and organize geospatial data that visualize spatial variations in DOI hazard exposure and deliver this information in ways that support DOI strategic-planning needs.

The intended outcomes of this effort include:

- Geospatial data and map products that visualize variations in hazard exposure of DOI assets, resources, and land;

- A multi-hazard risk assessment that helps the DOI OEM to determine national and regional needs for focused 
program resources, funding, training, and exercises. This data will help OEM fulfill requirements of Federal Continuity Directive 1 (FEMA, 2017) to incorporate risk management principles into planning;

- The identification of hazards that may require hazardspecific annexes in the DOI Baseline Operational Plan, which helps the DOI meet statutory requirements of 6 U.S.C. $\S 753$ to develop capabilities in support of the National Response Framework;

- A shared understanding of currently available data and products (2018) that characterize hazard and risk, as well as data and products that could be further developed; and

- Continued growth of USGS capabilities to apply science and develop products to help protect the safety, security, and economic well-being of the Nation by describing, documenting, and increasing understanding of natural hazards and their associated risks (DOI Departmental Manual, 2011; Ludwig and others, 2018).

In addition to the tasks outlined above, a long-term goal of this project is a sustained effort to inform the Department's emergency managers, resource managers, facility managers, and executives of risks posed by a wide range of hazards to departmental assets. The project currently focuses on providing information for strategic planning and is not meant to provide real-time or near-real-time information to support response efforts. However, the assembled data, products, and visualizations provided by this project may offer important information for situational awareness for operational response. Interactions among project contributors will also provide insight on interest levels and informational needs for response efforts, which could be developed with additional resources and increased engagement within the DOI community.

\section{Workshop Goals}

The SHIRA Project focuses on a wide array of hazards and assets to characterize and communicate DOI risks; therefore, engagement from a diverse group of DOI subject matter experts (SMEs), managers, and executives is integral to project success. A workshop was held on February 27-28, 2018, at the Main Interior Building in Washington, D.C., to gather input from DOI Bureaus and Offices and SMEs (appendix 1) on authoritative hazard and asset data sources and on ways to characterize and communicate risks that would best serve DOI's short- and longterm needs. The workshop was envisioned as the beginning of a long-term conversation among DOI Bureaus and Offices about threats to DOI assets and resources. The workshop goals were to (1) determine how DOI Bureaus and Offices use risk information for strategic planning and decision-making; (2) understand what types of information would be most useful to DOI Bureaus and Offices; (3) identify the most effective methods for data delivery and visualization; (4) establish what products are desired; and (5) collect ideas for future project directions.
To achieve these goals and tailor the workshop to DOI Bureaus and Offices, the SHIRA Project planning team held a series of phone conversations with key stakeholders in advance of the February 2018 workshop. These conversations allowed the SHIRA team to identify and address concerns or misconceptions about the project, as well as to determine agency-specific needs or interests. The resulting workshop agenda included time to address the following (see appendix 2 for full agenda):

- DOI assets and interests related to (a) human populations, (b) infrastructure, buildings, and critical facilities, (c) natural resources of economic value, (d) habitats and lands owned or managed by DOI, and (e) cultural assets;

- Ways to characterize the suite of biological, meteorological, geophysical, technological, adversarial, and wildland fire hazards, as well as the role of secondary, coupled, and compounding hazards;

- Approaches to characterize risk based on the integration of DOI lands, assets, and resources with hazard zones;

- Characteristics of products that would be most useful to DOI Bureaus, Offices, and partners, in terms of content (what information is desired), form (how results should be organized), and delivery mechanism (how results should be shared);

- Analytical challenges and potential solutions to integrate jurisdictional, hazard, and asset data in meaningful way;

- Potential for a community of practice within the DOI that could be focused on nationwide hazard/risk analysis to make this work transferable and scale-able to DOI Bureaus, Offices, and partners such as tribal, state, and other Federal agencies; and

- A forward strategy for collaboration that is desirable, practical, and achievable for all parties involved.

\section{Report Purpose and Scope}

The purpose of this report is to summarize the results of the February 27-28, 2018 workshop in support of the SHIRA Project. The results described herein reflect the input of workshop participants whose insights, while diverse, are not intended to represent the entire perspective of each DOI Bureau or Office or the DOI as a whole-room size and other logistical concerns limited the number of attendees. The SHIRA team acknowledges that further outreach must be done to capture the unique insights of DOI staff who were not able to attend the workshop. Continued engagement with a broad group of DOI Bureaus and Offices will contribute to the shortterm success and long-term relevance of this project. 


\section{Workshop Development}

\section{Framing Risk}

The SHIRA Project focuses on assessing risk to DOI assets. However, risk is perceived in different ways by individuals and organizations based on experience, culture, and other factors. Likewise, risk is defined in many ways by various fields of research and practice dependent on emphasis, needs, and objectives. Risk is often used to describe a hazard, a probability of occurrence of an event or adverse outcome, the probability of failure of a specific asset, the larger societal impacts if an adverse event occurs, or as a cost-benefit analysis of a proposed course of action. This wide range of risk perspectives can create confusion, disagreement, or misperceptions as to what an assessment should cover or how results should be communicated to decision makers. Therefore, having an agreed-upon definition of risk helps frame later decisions on data requirements, analytical approaches, and products. For the purposes of this project, we define risk as the potential for consequences where something of value is at stake and where the outcome is uncertain. It results from the interaction of a hazard with an asset of societal importance. This description of risk is inclusive for a range of hazards that may vary in their ability to be quantified, mapped, and compared in meaningful ways.

Characterizing risk is a complex, subjective endeavor because such analyses require decisions on the kinds of hazards, areas of interest, and assets to include; decisions on the approaches to qualify and/or quantify known risks; and decisions on how risk information will be shared and used. Approaches to characterize risk vary, ranging from a threat assessment to determine the presence or absence of a hazard to a mitigation assessment to determine the cost-benefit of potential risk-reduction interventions (fig. 1). The appropriate approach for a given project will vary based on the intended use of the results of analysis, such as general risk awareness to managers, policymakers, and the general public; preparedness and response planning; resource prioritization at various scales; and site-specific mitigation. For example, probability-based approaches may be required to inform decisions related to insurance and building-level mitigation but may be less useful in decisions related to evacuation planning and response training. Data availability may also limit the type of risk characterization that can be conducted; for example, the probabilities of a hazardous event occurring at a specific location, of an asset being damaged, or of a larger system failing are unknown or unknowable for certain hazards.

A goal of the SHIRA Project is to deliver risk information that helps the DOI OEM determine national and regional needs for focused program resources, funding, training, and exercises. The emphasis is on national-level comparisons of hazards and their potential impacts to DOI assets. Not all hazards of DOI concern can be mapped in meaningful ways and are discussed in more detail later in the report. Therefore, various approaches will be used to compare threats and potential DOI impacts. A relative threat matrix will provide a holistic risk perspective by comparing hazards based upon the capability of DOI personnel to minimize impacts and respond effectively when events do occur. For hazards that can be mapped in meaningful ways, analysis will focus on exposure assessments to quantify the type and amounts of DOI assets and resources in hazard zones. Some insight on the vulnerability to individuals, specific facilities or species, and system networks can be inferred from these threat and exposure assessments, however, more-detailed studies would be required to fully characterize vulnerability aspects of system sensitivity and adaptive capacity to specific hazards. Risk assessments, as traditionally defined by probabilistic approaches, are currently

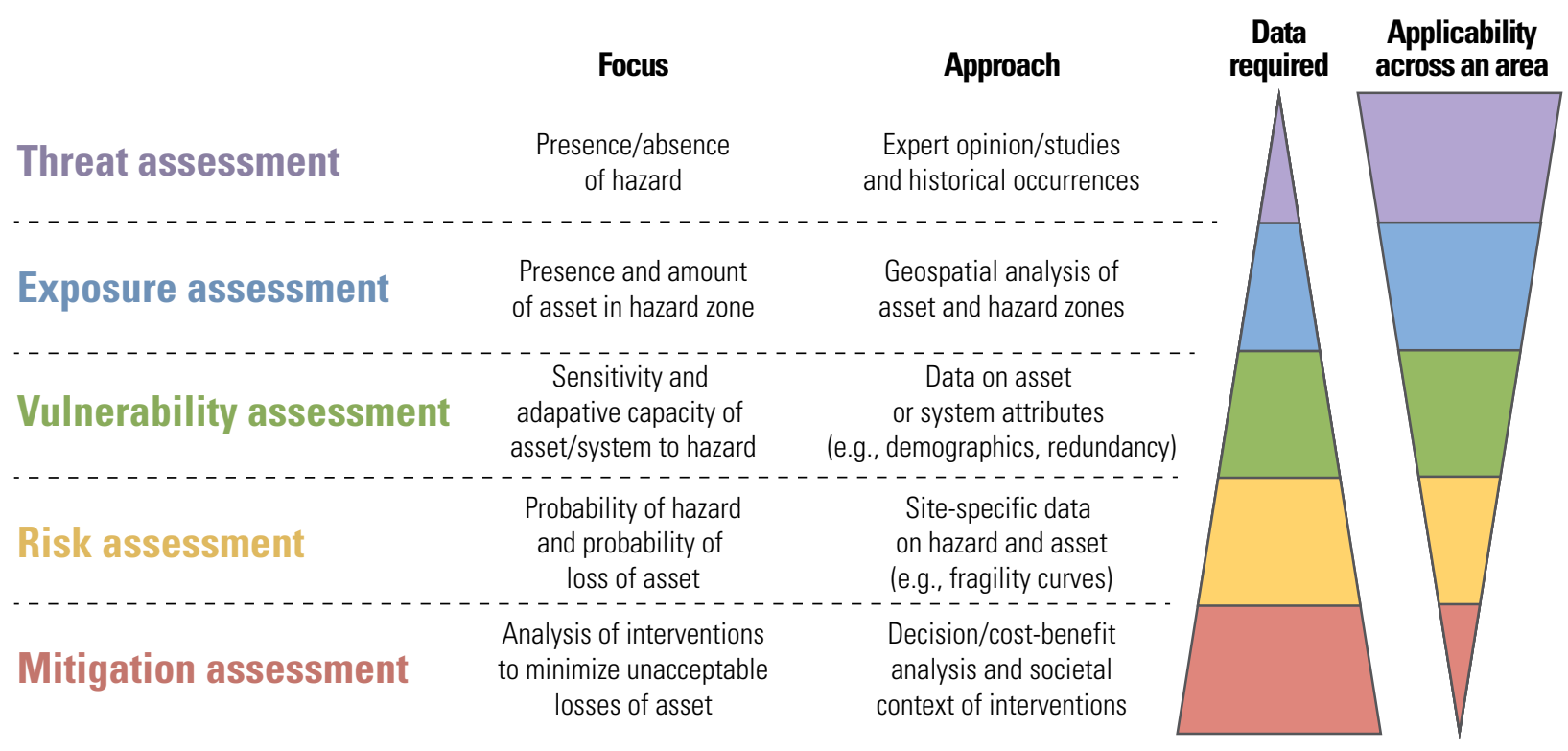

Figure 1. Spectrum of approaches to characterize societal risk from hazards. 
beyond the scope of the SHIRA Project given the lack of detailed asset information (for example, structural types and elevations) and lack of consistent probability information across all of the hazards of concern. Finally, mitigation assessments are best suited for site-specific decisions, rather than nationwide assessments, where detailed asset information can be quantified, such as the benefits and costs for alternative, risk-reduction interventions.

The intent of the SHIRA Project is that the threat and hazard-exposure assessment will provide a nationally consistent foundation of data and analysis that supports strategic planning but also identifies opportunities and needs for local vulnerability, risk, and mitigation assessments. Results of the hazard-exposure assessment will provide a blueprint for where additional studies, resources, and partnerships are warranted. Given additional resources, the assembled data and visualization efforts that contribute to the strategic hazard-exposure assessment could be adapted to support other DOI uses, such as risk monitoring and operational use.

\section{Types of Hazards and Assets}

Hazards of concern to the Department were identified as a part of the initial scoping process for this project. To develop a working list of hazards of concern, USGS and OEM convened a meeting of departmental emergency managers in August 2017. More than forty emergency management representatives from a variety of bureaus and offices attended this meeting. The group first reviewed the list of hazards identified by FEMA for the SNRA and removed hazards that were not pertinent or actionable for the Department. The group then identified hazards that were not a part of the SNRA but were important to the DOI mission (for example, wildlife disease outbreak). Once this list was compiled and reviewed by the participants, a document describing each of these hazards in more detail was circulated with the Senior Executive Emergency Management Council (SE-EMC) and Emergency Management Council (EMC) members for review and approval. A total of 36 biological, geophysical, wildfire, meteorological, technological, and adversarial hazards were identified for analysis through this process (fig. 2).

Identifying assets of importance to the Department initially followed a less structured process due to the limited time allotted for project scoping. The SHIRA team identified six categories of assets: human life safety, facilities, infrastructure, natural resources, cultural resources, and economic resources (fig. 3). These broad categories are being used to direct data collection and organization; however, this list may evolve over the course of the project through continued engagement with DOI Bureaus and Offices.

Using the approved list of hazards and the provisional list of assets, the USGS team developed a proof-of-concept analysis for the Department in September 2017. This proof of concept demonstrated the types of risk products that could be created with further funding and support, including tabular data, heat maps, and interactive web-based tools. The proof of concept was funded for continued work in 2018.
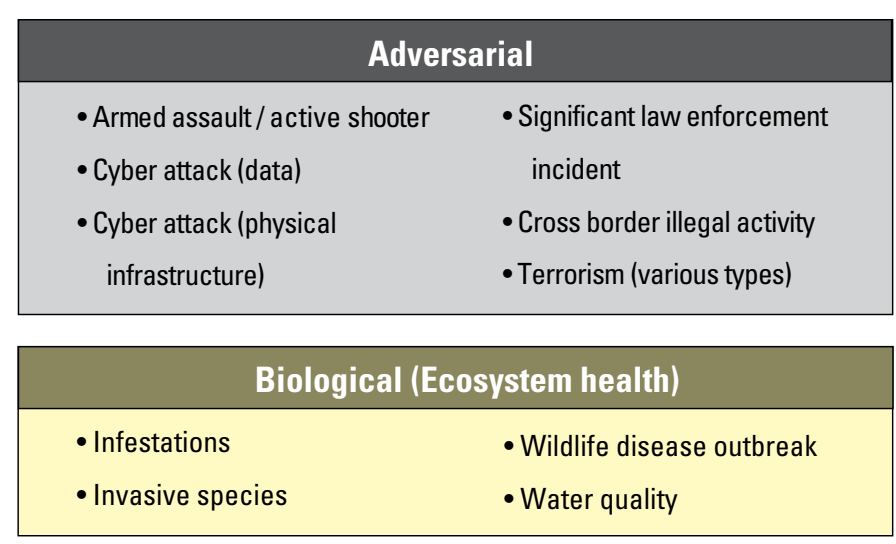

\begin{tabular}{|ll|}
\hline \multicolumn{2}{|c|}{ Biological (Human health) } \\
\hline$\bullet$ Zoonotic disease & $\bullet$ Human pandemic outbreak \\
$\bullet$ Toxicological disease & $\bullet$ Harmful algal blooms \\
\hline
\end{tabular}

\begin{tabular}{|ll|}
\hline \multicolumn{2}{|c|}{ Geophysical } \\
\hline - Coastal erosion/ inundation & - Space weather \\
- Earthquake & $\bullet$ Subsidence \\
- Flooding & $\bullet$ Tsunami \\
- Marine geohazards & $\bullet$ Volcano \\
- Landslide & \\
\hline
\end{tabular}

\begin{tabular}{|lc|}
\hline & Meteorological \\
\hline - Extreme heat & $\bullet$ Tornado \\
- Drought & $\bullet$ Other severe weather \\
- Winter weather & (for example, wind, hail, \\
- Tropical cyclone/hurricane & lightning) \\
\hline
\end{tabular}

\begin{tabular}{|l|}
\hline \multicolumn{1}{|c|}{ Technological } \\
\hline - Hazardous substance release \\
- Gas leak explosion \\
- Oil spill \\
- Uncontrolled well (gas or oil) \\
- Radiological substance release \\
- Infrastructure failure (for example, levee, dam, power grid, bridge) \\
\hline
\end{tabular}

\section{Wildland fire}

Figure 2. Seven hazard types approved by the Senior Executive Emergency Management Council (SE-EMC). 


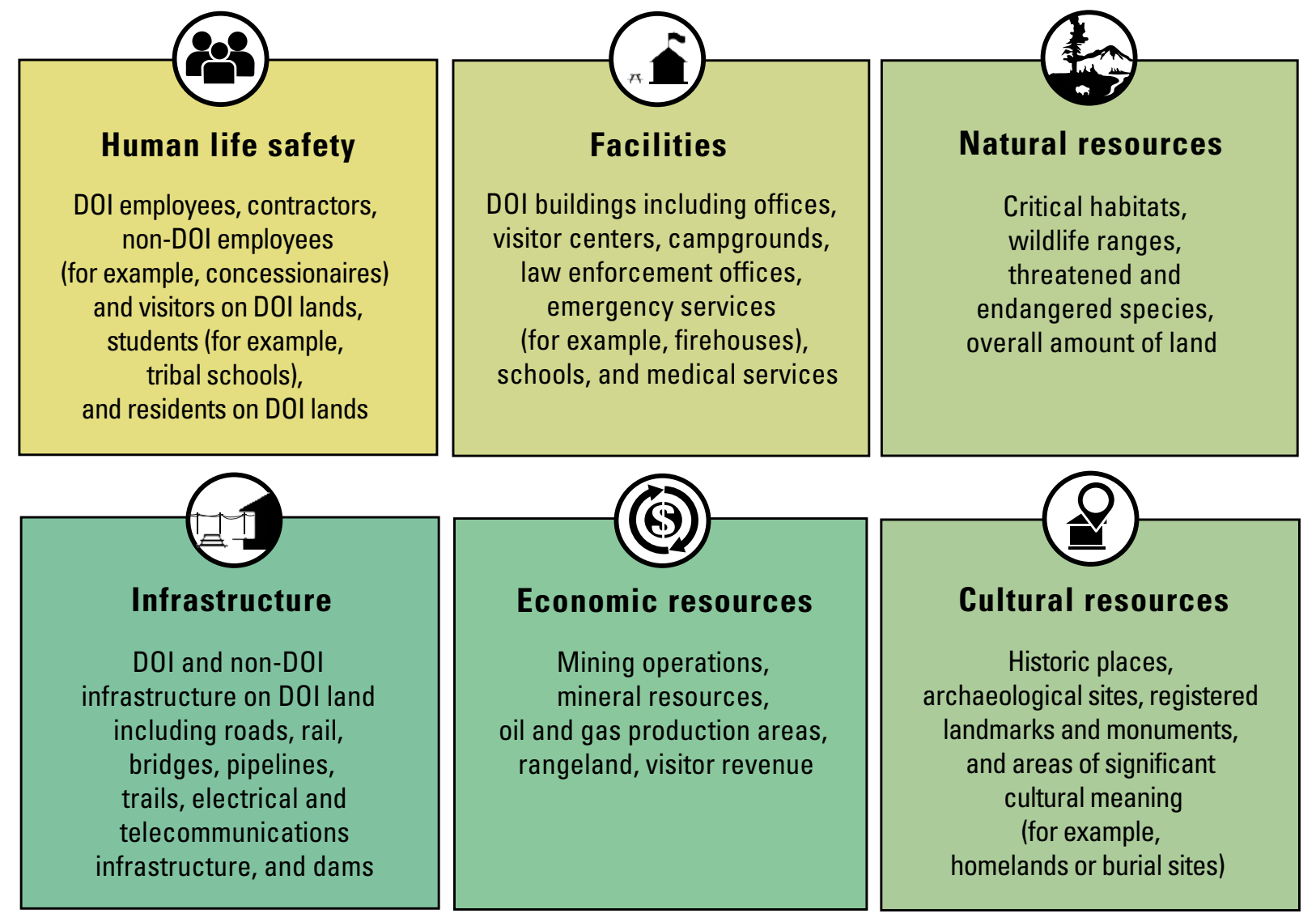

Figure 3. Categories of assets used at the February 2018 workshop.

Between September 2017 and February 2018, the USGS team worked to locate and collect pertinent datasets. The team also met with representatives from a variety of bureaus across the Department to better understand their needs for, and concerns about, this project, as well as identify potential workshop participants. This feedback was incorporated into the design of the February 2018 workshop.

\section{Participation}

The Department of the Interior comprises many bureaus and offices with wide ranging missions and assets of concern; therefore, the development of risk products that effectively inform DOI-wide risks requires broad engagement of those DOI Bureaus and Offices. As discussed earlier, meetings with various DOI Offices and Bureau representatives between September 2017 and February 2018 helped the SHIRA Project team gather input on potential workshop participants. The workshop had departmentwide participation with representation from the majority of DOI Bureaus and Offices (appendix 1). The 48 individuals at the workshop represented bureaus or offices with land management responsibilities (NPS, FWS, BIA, BLM) and those that manage DOI assets regardless of underlying land ownership (BIO,
BOEM, BSEE, FWS, IBC, OCIO, OEM, OEPC, OLES, PPA, OWF, PAM, USGS, and USPP). Attendees included emergency managers, resource managers, law enforcement officers, facility managers, data managers, geospatial analysts, economists, and subject matter experts related to hazards, ecosystems, public health, DOI natural and cultural resources, business administration, and DOI facilities and infrastructure (fig. 4). The workshop also included senior DOI leadership with opening remarks provided by the Deputy Assistant Secretary for the Office of Public Safety, Resource Protection and Emergency Services.

\section{Format}

The workshop agenda (appendix 2) was developed to maximize information gathering and discussion amongst participants. Formal presentations were limited to the morning of the first day and included opening remarks from the DOI and the USGS, overviews of workshop expectations and the SE-EMC approved list of hazards, as well as a framework of hazards, exposure, and risk that included examples from the geospatial proof-of-concept developed in 2017. The rest of the workshop was devoted to interactive exercises (fig. 5), including individual brainstorming, prioritization exercises, visualization exercises, and 


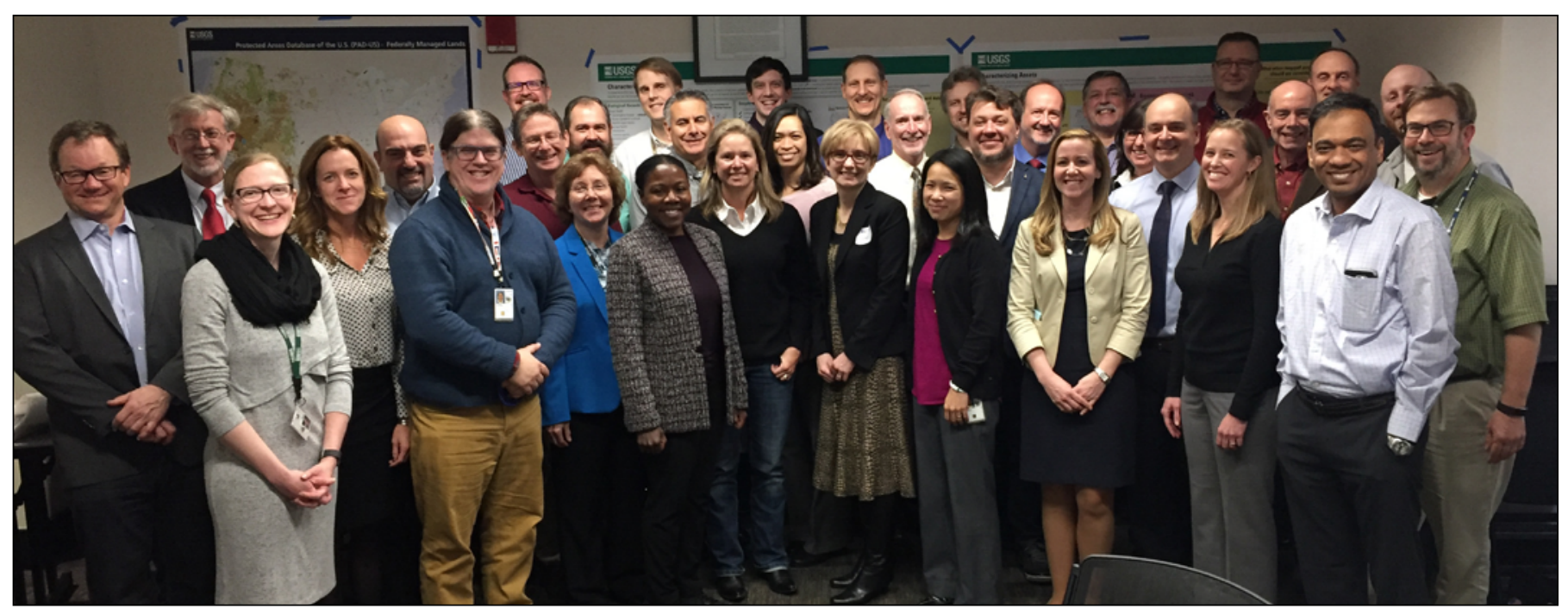

Figure 4. Photograph of many of the workshop participants. Photograph by Elizabeth Wasserman, USGS.

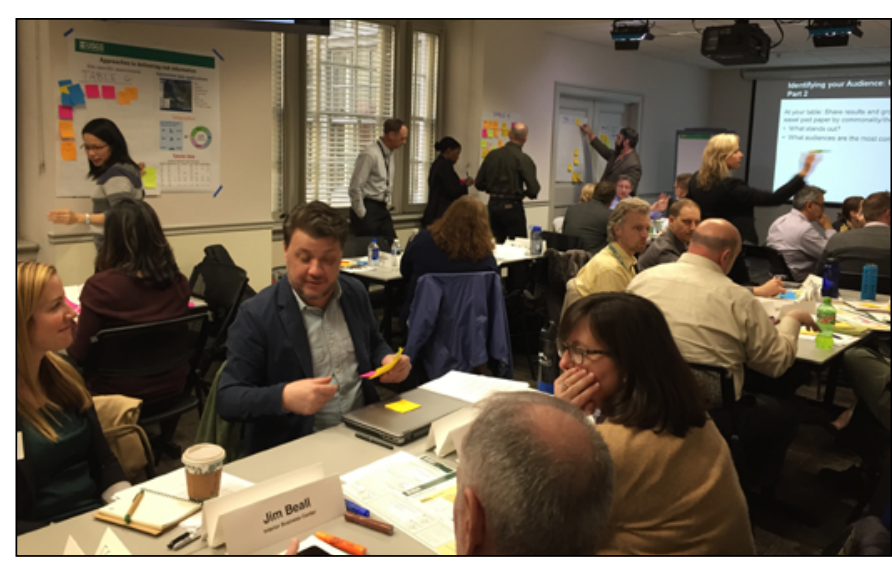

Figure 5. Photograph of table discussions during the workshop. Photograph by Nathan Wood, USGS.

group discussions (see appendix 3 for additional information on session formats and supporting workshop materials).

At the conclusion of the workshop, participants were asked to give feedback on workshop design via open-ended questions on what they liked and areas for improvement. Twenty-eight of the 48 participants provided feedback on a number of topics (fig. 6). Feedback was largely positive, demonstrated by the higher number of positive responses of what worked (66) compared to suggestions of areas for improvement (27). Participants were particularly positive about the level of interaction at the workshop, including the guided activities, the mix of people, and large-group and table discussions (fig. 6A). Suggestions on areas for improvement included a greater focus on the big-picture of DOI risk, as opposed to more detailed discussions of hazards and assets (fig. $6 B$ ).

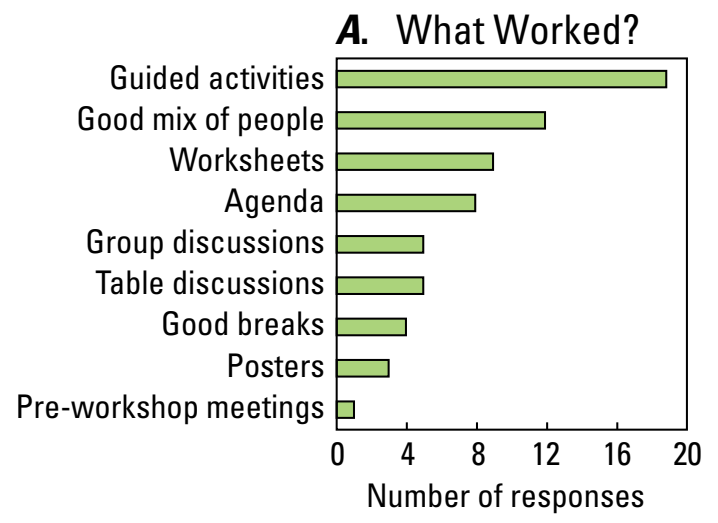

B. Areas for improvement

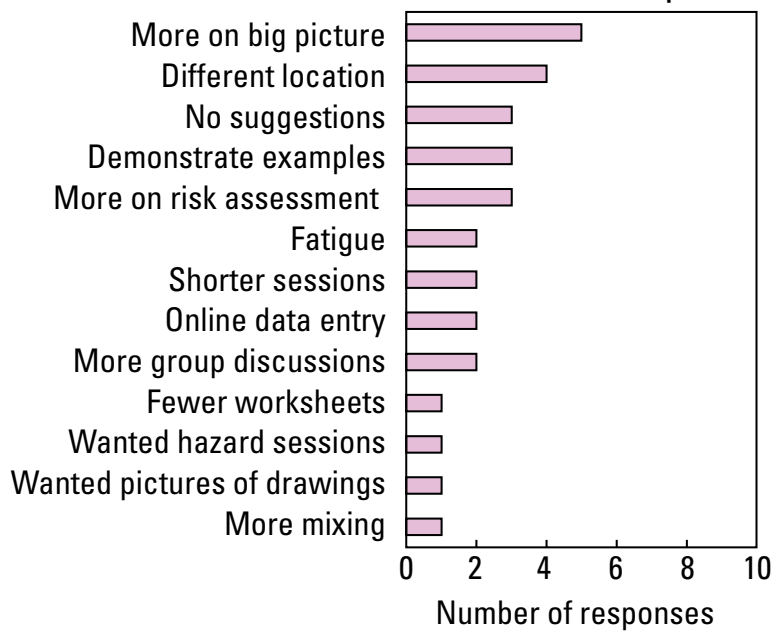

Figure 6. Participant responses on $(A)$ positive aspects of the workshop format, and $(B)$ areas for improvement in future workshops. 


\section{Workshop Results}

\section{Uses of Risk Information}

The first interactive session asked participants to think about the kinds of decisions or plans that they make in order to manage and protect various DOI assets, lands, and resources. The intent of this session was to gather input that would lead to the development of specific use cases for a risk assessment that supports the planning needs of DOI emergency managers, law enforcement officers, resource managers, and facility managers. "Use case" is a software engineering term for defining who potential users of a product are, their needs for that product, the frequency and conditions under which they might access the product, and the desired outputs of the product.

Participants were asked to provide (1) a specific risk-related decision or plan, (2) the kind of information that is currently being used to support these decisions/plans, and (3) what new information would be helpful to better inform these decision/ planning processes (appendix 3). Discussions at tables and with the entire group helped identify commonalities in use cases by different types of DOI planners or managers. Input from this session was used to develop a series of specific use cases that helped drive data collection, triage, and management efforts in 2018. Appendix 4 includes examples of the draft use cases being developed for the project.

Workshop responses indicated that participants saw value in risk-related information across all types of DOI concerns (fig. 7A). The highest number of decisions and plans discussed at the workshop focused on aspects of life safety for DOI employees and other individuals on DOI land (for example, visitors, nonDOI employees, residents, and school children). Within life

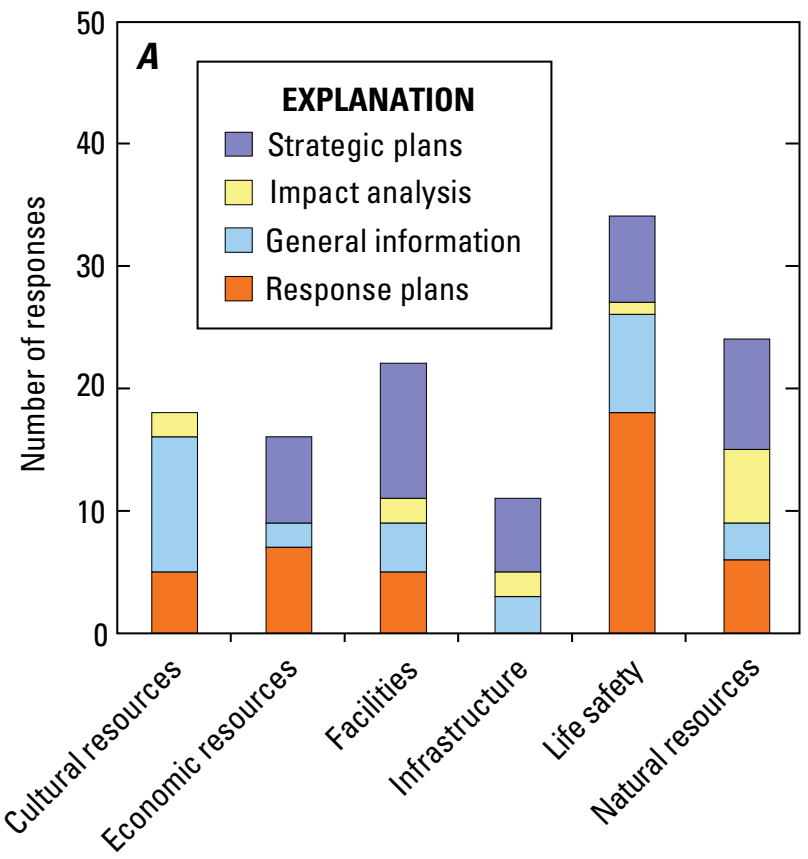

safety, response plans were the most common type of decision or plan. Across all types of assets, workshop participants focused equally on strategic plans and response plans, with less discussion of general information needs and impact analyses (fig. $7 B$ ).

For the various risk-related decisions or plans, workshop participants currently rely on inventories of assets, such as facility locations (fig. 8). For example, one participant described needing information on buildings, parking lots, and roads in hazard zones in order to make decisions as to whether or not these facilities should continue to be maintained. To a much lesser degree, workshop participants stated that they rely on forecasts and hazard zones, existing plans, historical data, SME input, vulnerability assessments, situational reports, and stakeholder input (fig. 8).

When asked what new data would be helpful in riskreduction planning, the greatest number of responses were related to hazard, vulnerability, or risk assessments based on currently available data (fig. 9). The second most-common response was improved inventories of structures and populations. A recurring theme during the discussions was the need to better understand not only the hazard exposure of facilities, but also their functional characteristics from a response perspective. For example, participants discussed an interest in knowing if facilities could serve as response centers or if they contained equipment relevant to an incident response. Therefore, a relevant risk assessment would provide insight into what facilities are in hazard zones, as well as on what nearby facilities may be safe and could still function to house response and recovery efforts.

\section{Audiences}

Strategic risk information is beneficial to many organizations, both internal and external to the DOI. To help

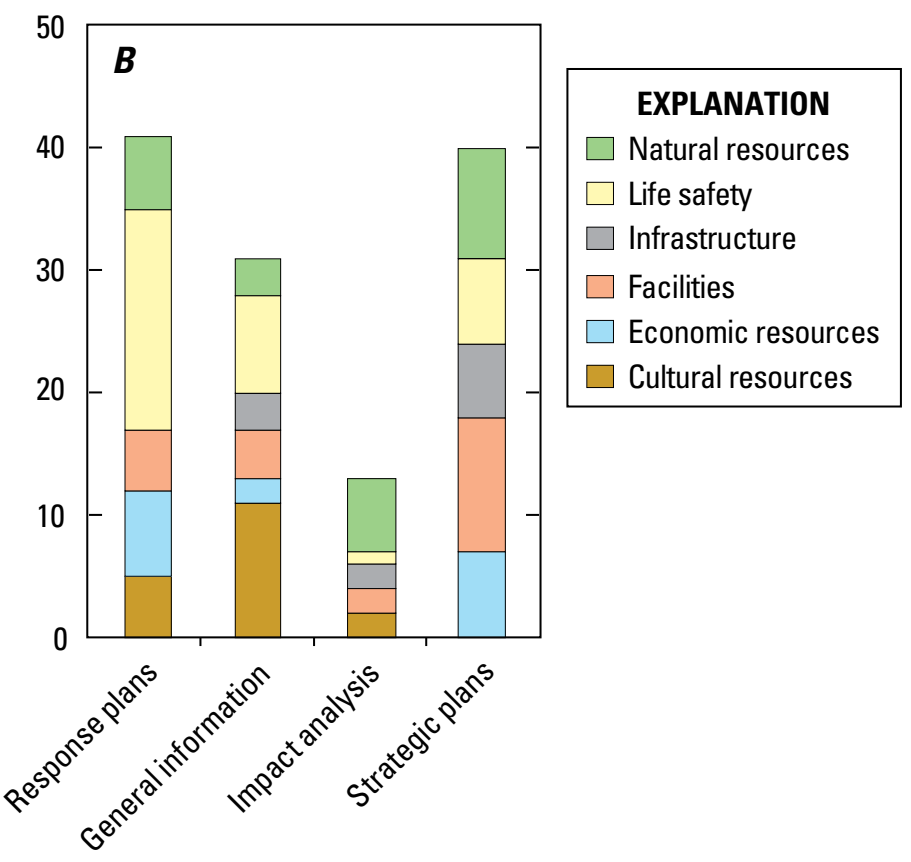

Figure 7. Types of decisions being made by DOI Bureaus and Offices, organized by $(A)$ asset of concern and $(B)$ decision type. 

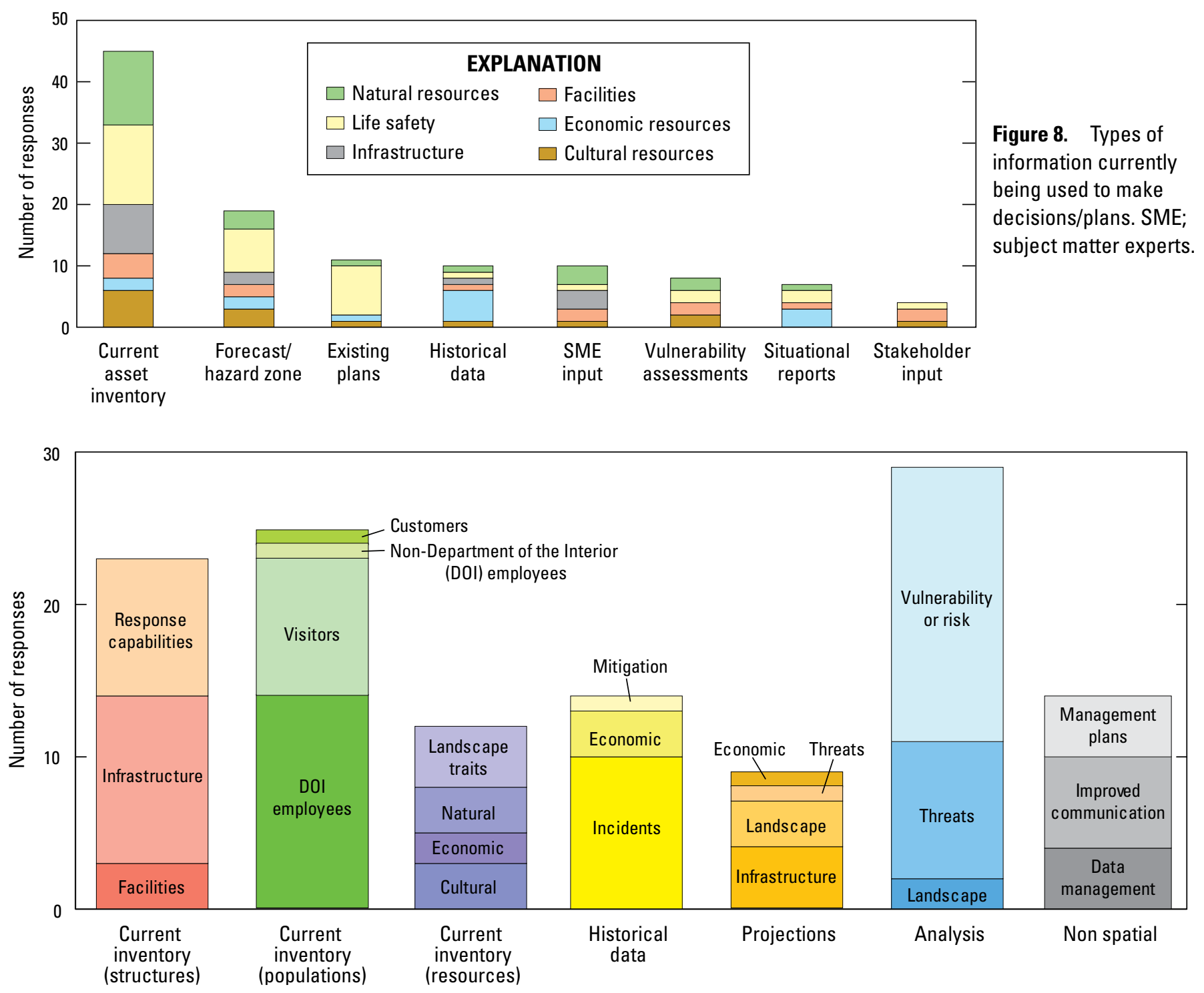

Figure 9. Participant responses on additional data needed to make decisions or strategic planning.

inform the development of use cases, workshop participants were asked to identify their key audiences for risk information (fig. 10). Responses indicated a wide range of audiences, including governmental agencies, non-governmental organizations, tribes, and academic partners (fig. 11). The audiences listed by the group were diverse, including: the FEMA National Response Coordination Center, Congress, Fish and Wildlife Refuge Managers, the Red Cross, the U.N. Food and Agriculture Organization, the public, media, park visitors, and U.S. Coast Guard. The most common response was the U.S. Federal Government (134 responses for DOI Bureaus/Offices and 87 responses for non-DOI entities).

Scale was an important factor in discussing the range of audiences. For example, "government organizations" included local, county, state, tribal, Federal, and even foreign governments. Participants saw a need to communicate risk information through various levels of DOI hierarchy from managers of individual units (for example, a FWS refuge or National Park) to Bureau and DOI senior leadership.

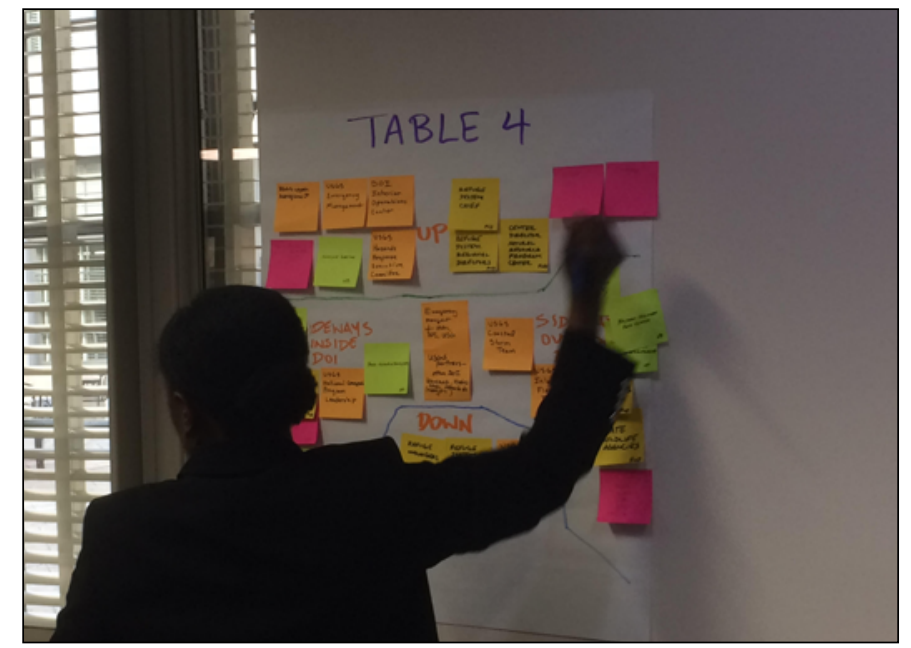

Figure 10. Photograph of a workshop participant discussing potential audiences for risk data. Photograph by Alice Pennaz, U.S. Geological Survey. 


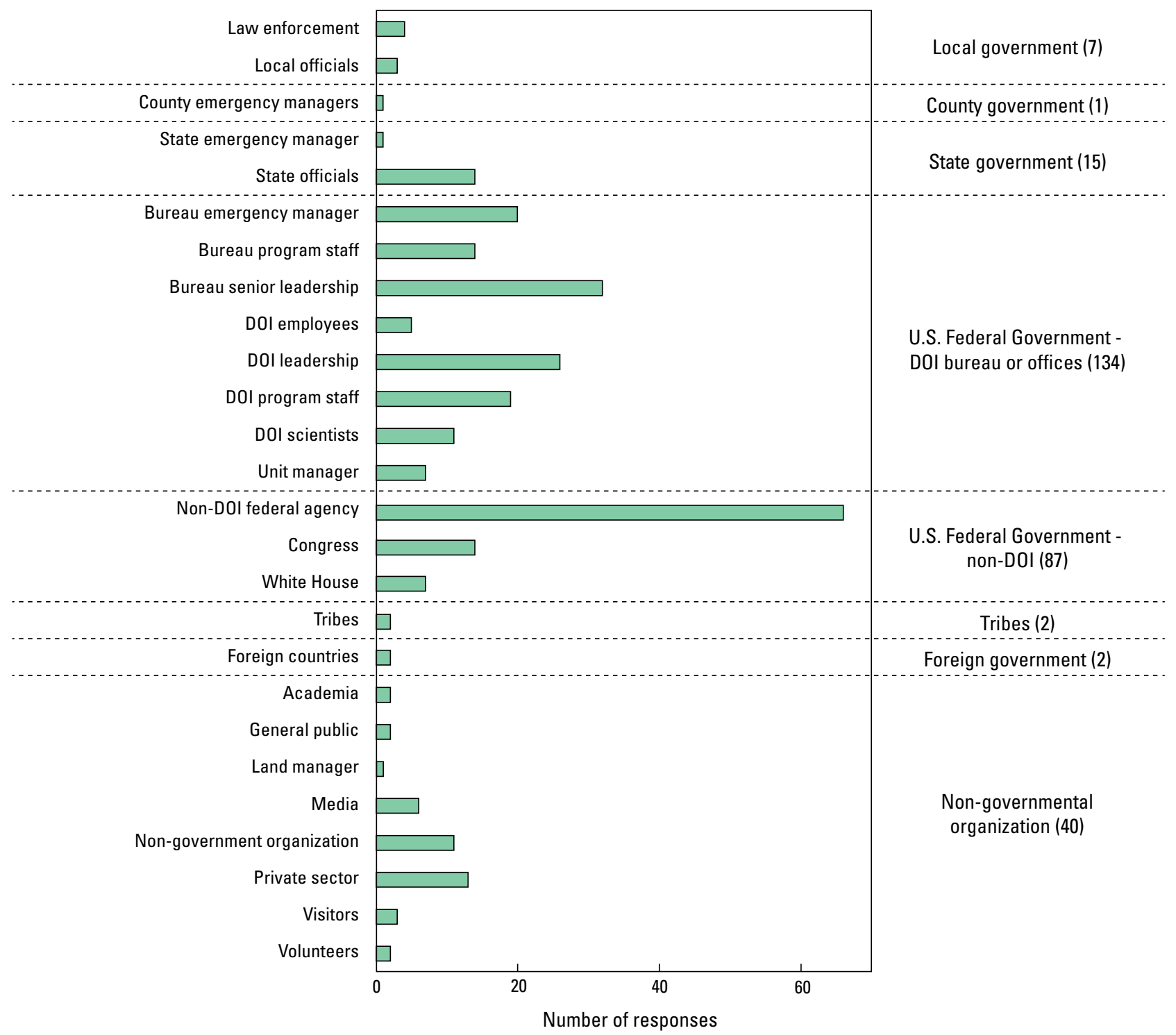

Figure 11. Types of audiences that would benefit from Department of the Interior (DOI) risk information and products.

\section{Identifying and Prioritizing Asset Data}

One of the main goals of the workshop was to determine what types of data or what specific datasets were most desired for planning and decision-making purposes. Creating this "data wish list" helps the SHIRA Project team to direct its efforts on data discovery and analysis. During the use-case activity, workshop participants were asked to identify data that they wished they had for making a decision or plan (fig. 12). Input on desired or relevant data for the DOI risk assessment was categorized as "recommended" if a source for the data was provided (for example, bureau name and point of contact) and as "requested" if no source was provided (that is, the data may or may not exist). In a subsequent session, they were presented with six broad categories of asset data (human life safety, facilities, infrastructure, natural, cultural, and economic resources) with examples provided for each category and were asked to note whether or not they desired further details on these broad categories. On the second

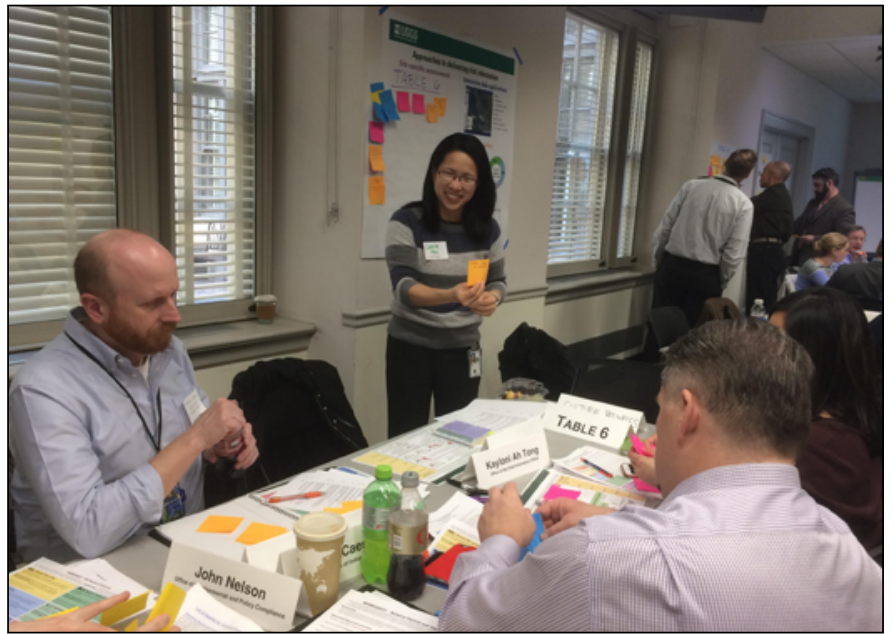

Figure 12. Photograph of a table discussion on data "wish lists" during the workshop. Photograph by Nathan Wood, U.S. Geological Survey. 
day of the workshop, participants were asked to look at lists of all requested data on the previous day and to identify their priorities.

Respondents listed a wide variety of assets information that they desired (for example, seasonal employee numbers, bird flyways, location and size of irreplaceable museum collections, age and elevation of facilities). A full list of requested and recommended data is listed in appendix 5 . Based on the prioritization exercise on Day 2, workshop participants were most interested in infrastructure, facilities, threat, and population data (fig. 13). Participants were generally more precise in their requests for infrastructure data (for example, telecommunications versus transportation and few general "infrastructure" requests) compared to facilities data, where approximately half of the responses in the category were for general "facilities" data.

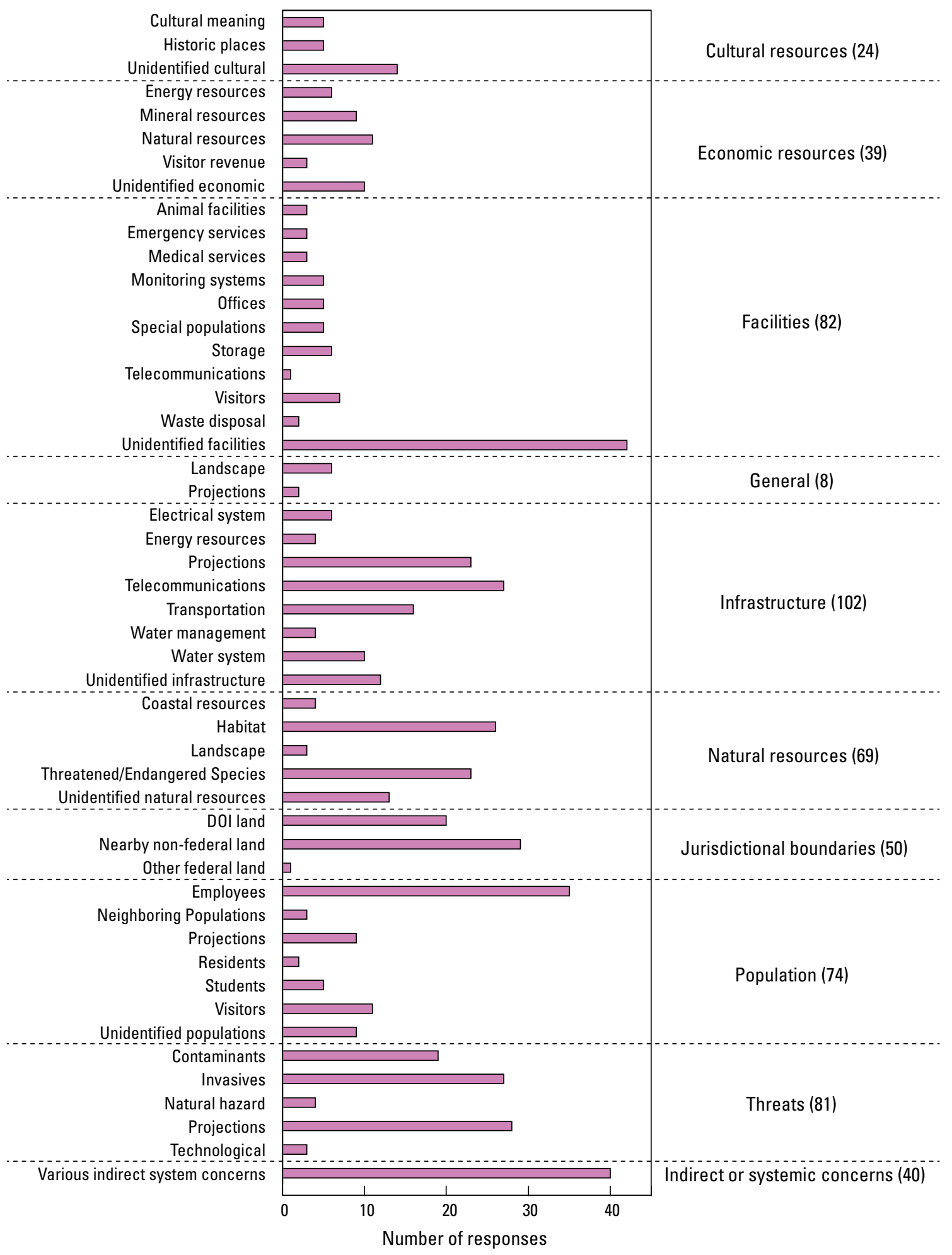

Figure 13. Types and priorities of data to inform Department of the Interior (DOI) risk. 
In addition to specific data requests, there were also several requests for more general information on systemic concerns, such as downstream and upstream effects of hazards, cascading and indirect effects of hazards, and critical interdependencies. This category of data was prioritized by 40 of 48 participants, indicating broad interest at the workshop. One example was a request for the SHIRA Project to characterize threats to migratory corridors for select wildlife species. In this case, as well as with providing information on upstream and downstream effects, analysis would need to expand beyond hazard-asset overlays to characterize hazard exposure and focus on network connectivity and sensitivity. As discussed earlier, these types of analyses would require characterizing the vulnerability of individual asset/species as well as entire ecosystems, in terms of sensitivity and adaptive capacity. Table and group discussions also highlighted interest in these systemic aspects of vulnerability and risk.

An important outcome of the data wish list exercises is that participants were able to describe data that could be beneficial to them but may not yet exist. This information will be communicated to DOI Bureaus and Offices to help guide future data collection or development efforts. Data discovery efforts by the SHIRA team will involve determining the availability of data requests listed in appendix 5. In some cases, datasets requested by workshop participants may never exist or be shareable if they do exist due to privacy issues (for example, home telework locations for all employees). Some data may be difficult to map due to the time-sensitivity of the data (for example, susceptibility to disease of wildlife populations). These requests introduced important opportunities during the workshop to discuss the limitations of available data for this project.

\section{Characterizing Hazards}

The SHIRA Project involves 36 biological, geophysical, wildfire, meteorological, technological, and adversarial hazards (fig. 2). All of these hazards represent credible threats to DOI assets; however, they are not equal in terms of their ability to be mapped to support strategic risk planning or in the ability to quantify their likelihood of occurrence within a decadal or human-lifetime scale. These differences impact the ability to compare hazards and assess hazard exposure to DOI assets, lands, and resources. For example, few hazards of DOI concern in the SHIRA Project have geographically explicit, long-term hazard assessments available at the national scale that can be used in a geospatial hazard exposure. The few that do include wildland fire hazards, potential inundation zones from levee or dam failures, and various geophysical hazards (for example, earthquakes, flooding, landslides, tsunamis, and volcanoes). One workshop session focused on gathering input from participants on how to address this challenge in characterizing and delineating all hazards of DOI concern in a consistent and meaningful way.

\section{Relative Threat Matrix}

One approach for dealing with disparities in hazard data availability is the use of a relative threat matrix that compares hazards based on common categories. Each category includes a range of characteristics that can be quantified using a relative scale (for example, a 1 to 5 ranking). SMEs can then estimate where a hazard falls on the relative scale for a specific attribute (for example, speed of onset with potential characteristics of instantaneous to minutes, hours, days, weeks to months, or greater than one year). The final matrix of category values can then be aggregated and used to produce a relative threat assessment. Threats can be ranked in order of importance if categories or certain attributes are weighted differently (for example, a higher priority may be placed on sudden-onset hazards that may kill people). If no weighting is used, then a threat assessment can group hazards based on similar attributes. DOI managers can then use the resulting classification system to develop risk-reduction strategies that address multiple hazards at a location.

Relative threat matrices are common in the computer sciences and in business strategic planning but often just focus on the likelihood of impacts compared to the magnitude of impacts. This approach of only using likelihood and magnitude is inadequate for the SHIRA Project for two reasons. First, estimating the geographic distribution and likelihood of impacts is difficult and potentially impossible for many hazards (for example, adversarial hazards). Second, the type and magnitude of impacts is highly variable and a simple comparison based on a single indicator would bias an assessment to the selected indicator. For example, potential impacts for hazards in the SHIRA Project can range from human loss of life from an individual active shooter to regional economic and ecological losses due to long-term drought conditions.

To provide a more complete perspective on comparing hazards, a workshop exercise (appendix 3) introduced the concept of a relative threat matrix and had participants provide input on a range of potential hazard attributes, as well as suggestions for other attributes to consider. The focus was not only on characteristics of the hazard or event itself, but also on the pre-event actions that DOI personnel can implement, available response efforts, direct societal impacts, and post-event recovery if an event were to occur. This approach allows for comparisons of hazards where mapped assessments are available (earthquakes and floods) with hazards where the location of future events are unknowable (an active shooter or an uncontrolled well). Once hazard categories and related ranges in attributes are determined, SMEs can then assess each of the DOI hazards of concern in terms of attributes that range from 1 to 5 in a relative scale. Hazard categories and their related, scaled attributes are then combined into a relative threat matrix that can be included with deliverables of the SHIRA project.

Based on input from workshop participants, the following is a list of potential categories and sub-categories to be assessed for each hazard. Appendix 6 includes an in-depth description for each of these sub-categories. The categories, sub-categories, and range of attributes discussed here and in appendix 6 will evolve based on continued discussions within the SHIRA Project team.

- Event characteristics, including frequency, likelihood, speed of onset, duration, temporal predictability, spatial predictability, ability to map hazard zones, and potential for cascading hazards; 
- Pre-event actions, including warning or detection ability and the ability to mitigate losses;

- Response actions, including the ability to control the hazard during an event;

- Direct impacts, including scale of impact, dread, and severity of impacts to people, facilities, infrastructure, cultural assets, ecosystems, and economic resources; and,

- Post-event characteristics, including cost of impacts, impact to DOI mission, legal implications, potential media exposure, potential benefits.

\section{Hazard-Mapping Challenges}

For the project's proof-of-concept geospatial analysis, hazard exposure of DOI lands and assets was based on "high" hazard zones for the subset of threats that had existing mapped zones. This was a simplification of the information available for certain hazards, as some have been mapped with ordinal scales (high, medium, low), and others have magnitude thresholds (for example, storm surge inundation relative to various hurricane category storms) that were subjectively assigned "high" hazard status. Labeling a hazard zone as "high" also over-characterized certain hazards that are simply mapped based on the presence or absence of a threat (for example, the historic occurrence of chronic wasting disease) without any less hazardous categories. One question for workshop participants focused on ways to better map zones for these hazards.

Workshop participants overwhelmingly indicated that having a range of classes rather than just an indication of presence/absence of high hazards would be useful to them (fig. 14). In particular, there was interest in the ability to filter and choose thresholds for particular situations, regions, or time periods. For example, emergency managers and resource managers may have different levels of concern for a given hazard due to different planning priorities. Participants noted several examples of hazards that could have multiple classes, including: hurricane storm surge (storm category or depth of surge), stormrelated flooding (100 year and 1,000 year events or flow rate/ depth), environmental contaminants/pathogens (high, medium,

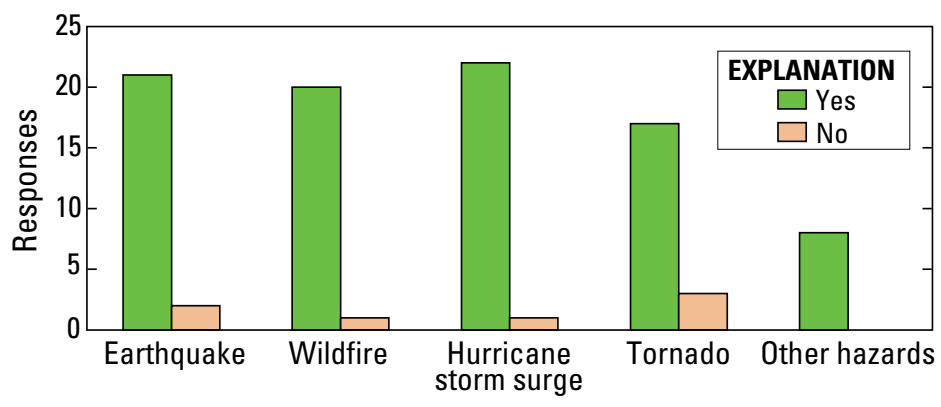

Figure 14. Workshop participant desire for range of classes other than high for a variety of hazards. low risk of spread), wildlife diseases and toxins (morbidity/ mortality rates), invasive species (consideration of top 10 individual species), and infectious diseases (mass mortality versus individual cases, habitat suitability for vectors, pathogens - ticks, mosquitoes, pathogens in still water, avian influenza).

\section{Other Hazard Sources}

As noted earlier, many of the hazards on the approved SE-EMC list lack mapped zones based on either deterministic or probabilistic assessments. Other data sources exist and could be used but their relevance in a strategic risk assessment warrants additional discussion with DOI Bureaus and Offices. These other potential data sources include:

- Maps of current status, such as snowfall accumulation or a harmful algal bloom;

- Inventories and maps of historic occurrence;

- Short-term forecasts available in terms of minutes, days, weeks, or months (for example, meteorological hazards, wildland fire, and some geophysical hazards); and

- Projections of certain hazards based on monitoring of emerging conditions, such as post-fire debris flows and volcanic ash.

Participants were asked to comment on how these various data sources may be relevant for the strategic risk assessment of the SHIRA Project. Workshop participants overwhelmingly indicated that historical data would be useful to them for several hazards (fig. 15). Participants noted that historical data could be used for trend analysis to gauge the relative frequency and seasonality of certain hazardous events. It could also provide information on potential legacy pollutants/contaminants from past hazardous incidents and show the concentration and spread of various diseases (for example, white nose syndrome, avian influenza, and fish diseases). During group discussions, participants specifically mentioned the utility of historic databases of snow, tornadoes, wind, landslides, earthquake debris flow, wildfire burn areas, heat, and geomagnetic storms. Workshop participants also expressed interest during table and group discussions in other data sources (current status, short-term forecasts, and projections based on emerging conditions) as well.

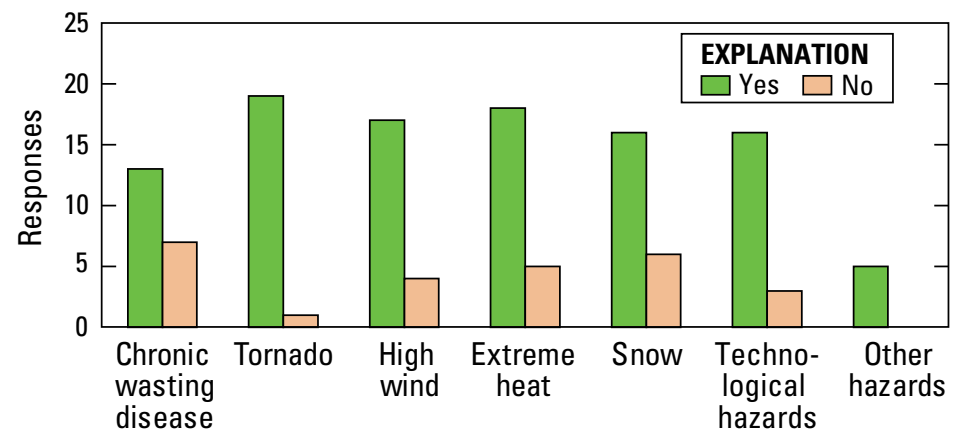

Figure 15. Workshop participant desire for data on historic occurrences of various hazards. 


\section{Additional Hazard Sub-Categories}

The SE-EMC approved list of hazards (fig. 2) is a starting point for characterizing DOI risks; however, some of the listed hazards comprise several distinct hazards that may have different physical characteristics and potential impacts to DOI assets, lands, and resources. The volcanic threat hazard to DOI assets is an example, in that it represents several distinct hazards which have very different hazard profiles and potential impacts. For example, ash associated with eruptions can last for days, impact global air travel, and affect the economies of countries throughout the world. In contrast, lahars, which are destructive land-based debris flows or mudflows that may or may not be related to an eruption, arrive very quickly, are deadly to humans, destroy buildings, but are generally confined to river valleys on the flanks of a volcano. Therefore, combining these two very different hazards under a single category of "volcano hazard" may over-simplify the threats that they pose to DOI assets, lands, and resources.

Most workshop participants agreed that it would be useful to have sub-categories for certain hazards (fig. 16). Participants identified and divided geophysical hazards into the sub-categories volcanoes (ash versus lahar), earthquakes (ground shaking, liquefaction, landslides), and landslides (debris flow, rockfall, creep).There was also interest in further classifying wildland fire hazards (burn area, debris flow, floods, smoke, ash, and particles), hurricanes (storm surge, rainfall/flooding, and wind damage), toxic materials (differentiated by type or by explosive versus smoldering), and invasive species (individual species or by larger taxonomic groups). During the group discussion, there was considerable interest in the SHIRA Project being able to articulate cascading hazards, such as a cyberattack that causes a dam release and subsequent flooding of downstream communities and ecosystems.

During the various discussions about hazard data sources, a consistent topic was the need for acknowledging regional variations in hazard thresholds. Recent histories of extreme events and the current adaptive capacity of communities influence what constitutes a hazard in a risk assessment. For example, two feet of snowfall accumulation may be a common occurrence in the U.S. Northeast and as a result, communities there may have experience and sufficient snow-clearing equipment to deal with similar snowstorms. Therefore, a "snow hazard" for the U.S.

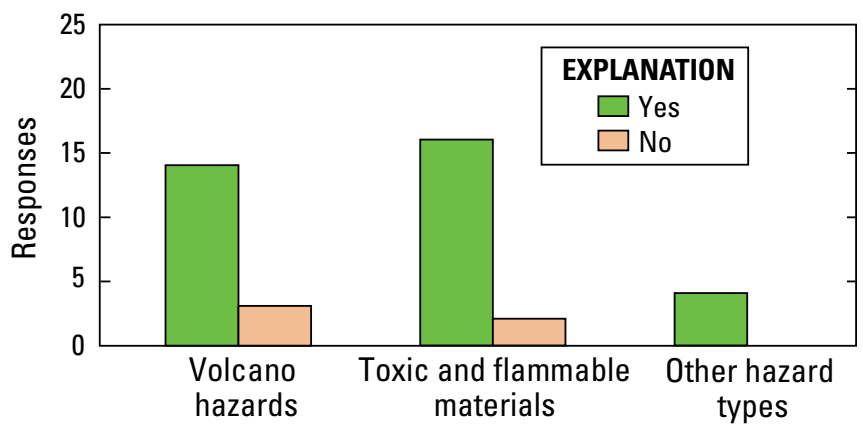

Figure 16. Workshop participant desire for further classification of a hazard.
Northeast may be snowfall accumulation in excess of this amount. Conversely, due to the rarity of snow and the lack of snow-clearing equipment, communities in the U.S. Southeast or elsewhere may consider two inches of snow accumulation in a given time period to be a significant threat to life safety and local economies. The SHIRA Project team will continue to discuss the possibility of regional thresholds in the analysis.

\section{Delineating DOI Land and Resources}

The goal of the SHIRA Project is to characterize the hazard exposure of DOI assets of concern. However, many of these assets are not owned or otherwise controlled by the Department. For example, bureaus with land management responsibilities are concerned with the life-safety and human health of not only DOI employees but also of tribal community members, visitors to DOI lands, and concessionaires and other non-DOI employees on DOI land. There is also considerable infrastructure (for example, roads, rails, and pipelines) that is owned by other agencies or organizations but are located on DOI land and if damaged, could impact DOI assets and resources. Characterizing DOI hazard exposure therefore requires a consistent interpretation of what land constitutes "DOI land and resources."

The Protected Areas Database of the United States (PAD-US) is the official inventory of protected open space in the United States and includes all DOI holdings (Gergely and McKerrow, 2016). It includes land administered or managed by DOI Bureaus (BLM, FWS, NPS, BIA, Reclamation) and land managed by these bureaus in coordination with other agencies or organizations (fig. 17). Discussions over the course of the workshop revealed that limiting the analysis to land owned by DOI Bureaus in the SHIRA Project exposure assessment would greatly underestimate exposure across the country, largely due to the fact that the BIA is responsible for the administrative and management of land held in trust by the United States for Native American and Alaska Native Tribes but the BIA does not own the land. Therefore, tribal concerns would be unintentionally excluded if only the "DOI owned" lands were included. Conversely, using the "DOI managed" classification in PAD-US would overestimate hazard exposure because DOI Bureaus co-manage millions of acres with

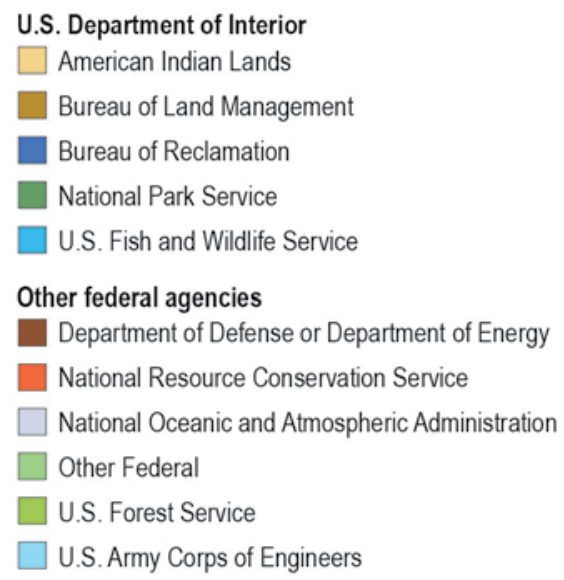




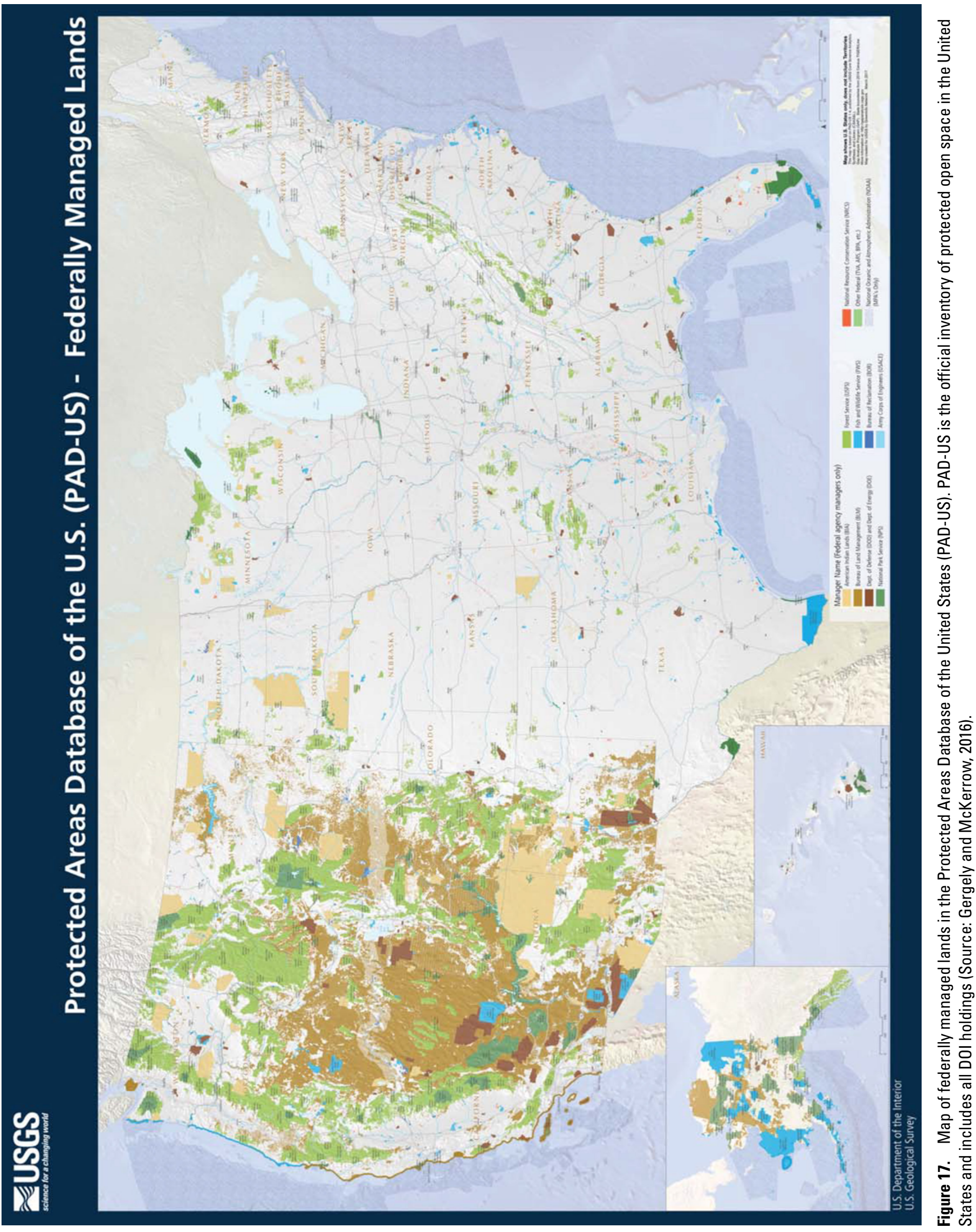


other national, State, and some local governments, and by some nonprofit conservation organizations. Therefore, a hazard exposure based on the "DOI managed" classification would inappropriately include entire communities and habitats.

Based on workshop discussions, the SHIRA hazard exposure related to non-DOI assets on DOI land will be based on the "DOI owned" for BLM, FWS, NPS, and Reclamation and supplemented with the "DOI managed" lands for BIA interests. This means that these geographies from the PAD-US will be used to extract data from non-DOI datasets, such as U.S. Census Bureau residential population counts, the U.S. Army Corps of Engineers National Structure Inventory, the U.S. Department of Homeland Security critical facility and infrastructure data, and third-party proprietary business databases.

In addition to terrestrial resources delineated in PAD-US data, the DOI also has responsibilities related to managing natural resources on submerged lands. For example, the Bureau of Ocean Energy Management (BOEM) manages development of energy and mineral resources found within the U.S. outer Continental Shelf and the Bureau of Safety and Environmental Enforcement (BSEE) works to improve safety and ensure environmental protection related to the offshore energy industry. During the workshop, BOEM and BSEE representatives were interested in several aspects of risk, such as the safety of non-DOI personnel on offshore oil and gas drilling platforms and hazards that could damage the platforms. Other examples of offshore DOI resource are NPS Marine Protected Areas, which are marine reserves that may be open for public enjoyment but may limit or prohibit consumptive activities (for example, fishing). Including offshore resources, such as marine protected areas and energy extraction platforms, in the DOI risk assessment is challenging, given the lack of hazards data for offshore areas, the dynamic nature of relevant threats (for example, currents and wave climates), and the proprietary data associated with private businesses that are developing the oil and gas resources. Therefore, offshore DOI resources are considered outside the scope of the initial risk assessment but could be included in future assessments as the SHIRA effort matures within the Department.

\section{Hazards Exposure Overlays}

The hazard-exposure analysis being completed for the SHIRA Project involves the compilation of a substantial amount of geospatial data representing hazards, administrative boundaries, and DOI assets and resources. An integral step in transforming all of the data into actionable information is understanding what combinations of data are most useful in DOI risk-management efforts. Thus, workshop participants were asked to select hazard-asset overlays that would be most relevant in their planning and decision-making processes. Participants were asked to identify these potential overlays because not all combinations of data are useful. For example, having information on facilities in an earthquake hazard zone might be more useful than information on facilities located in zoonotic disease hot-spots. Information on the most relevant geospatial combinations of hazards and asset data will inform the products that are developed for the Department.

Thirty-three workshop participants provided input on 210 potential combinations of hazards and assets (appendix 3 ). The greatest amount of responses that a specific hazard could receive during this prioritization exercise was 198, based on 33 participants and 6 types of assets (human populations, facilities, infrastructure, natural resources, cultural resources, and economic resources). Results indicate that asset overlays with geophysical hazard zones were the most common responses, including floods (109 responses), earthquakes (108), landslides (104), and tsunamis (101). Hazard exposure from tropical cyclone and hurricanes, wildfires, and terrorism also received a high number of responses (fig. 18). Space weather received the lowest number of responses. Over the course of this exercise and other workshop exercises, participants also identified concerns over cascading hazards such as flooding that can lead to water quality issues and harmful algal blooms, or an earthquake that impacts a pipeline, creating an uncontrolled well that subsequently impacts critical habitats.

Responses from this exercise were grouped to understand what assets were of most interest, regardless of the hazard. The highest number of responses that a specific asset could receive in this aggregation was 1,188 responses, based on 33 participants and 35 types of hazards. Results indicate that human populations, including DOI employees and anyone on DOI land, received the highest number of responses (fig. 19). Approximately half of all participants highlighted human populations for the hazardexposure analysis. Facilities, infrastructure, and natural and economic resources had a similar number of responses. Cultural resources had the fewest number of responses, although this may reflect the few cultural resource SMEs present at the workshop.

\section{Scale of Relevant Risk Information}

The current SHIRA effort focuses on providing risk information for national-level strategic planning. However, to inform national-level planning, the hazard exposure of individual assets and resources must be estimated and then aggregated for results of national meaning. Workshop participants were asked if the underlying data and analytical results would be useful at different scales in other risk-related planning efforts. Responses from 32 workshop participants indicate that they do want information at multiple scales (fig. 20). The most responses were for information at the individual building level and at regional scales. Participants provided comments on specific scales at which risk information would be relevant, including individual assets (for example, a specific building), a unit (for example, a FWS refuge), a state (primarily for interactions with FEMA colleagues) and regional delineations (for example, an Outer Continental Shelf region). With regard to regional summaries, a common request during the group discussion was the availability of information at the watershed level and by DOI regions. 


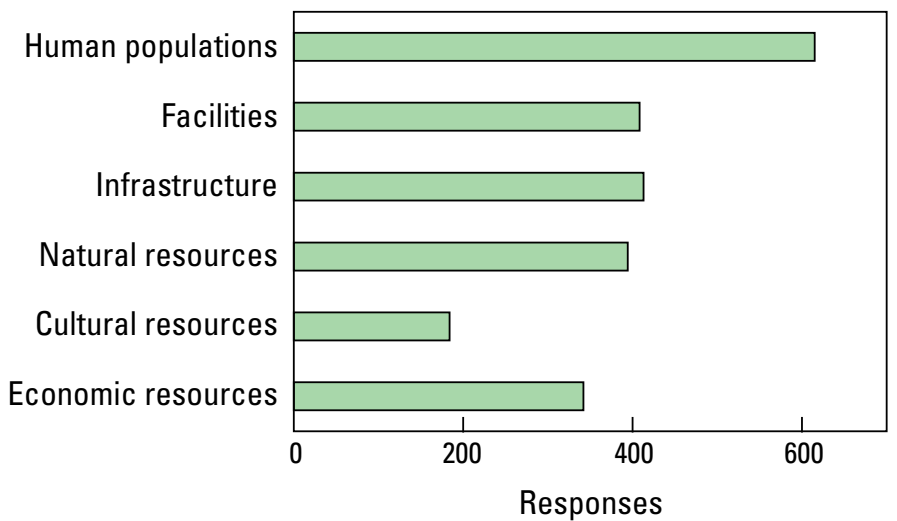

Biological hazards (human health)

Biological hazards
(ecosystem health)
Wildlife disease outbreak
Water quality

Terrorism

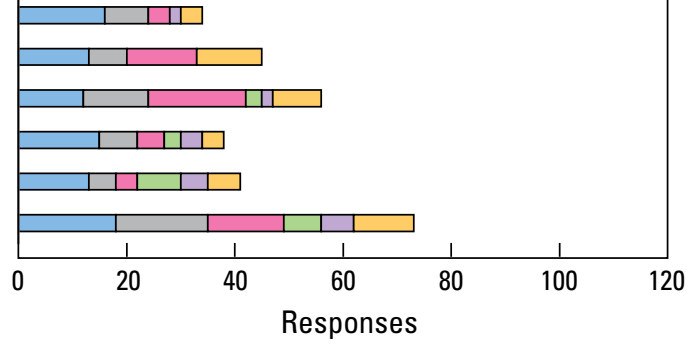

Zoonotic disease

Toxicological disease

Human pandemic outbreak

\section{s}$$
\text { s }
$$

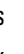
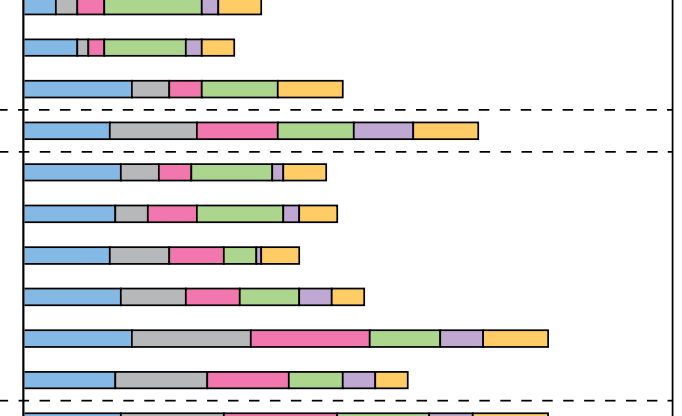

$$
\text { - }
$$
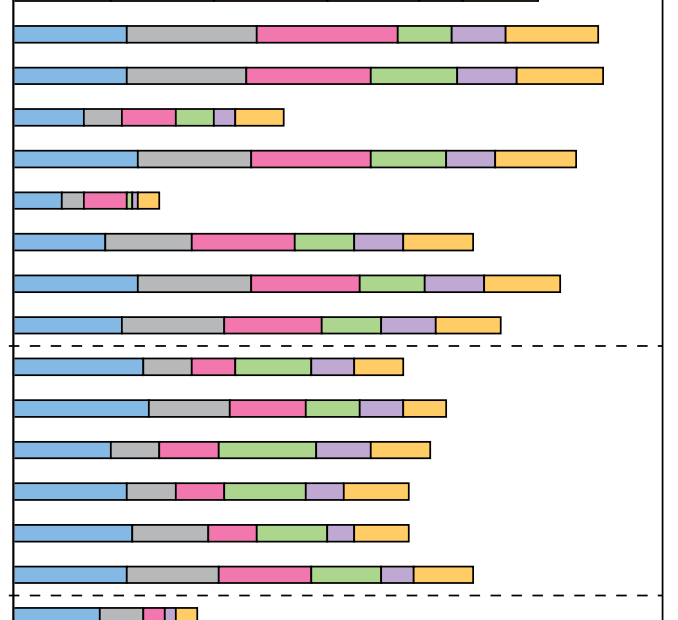

Figure 19. Assets information desired by workshop participants.

\section{EXPLANATION}

$\square$ Human populations

$\square$ Facilities

$\square$ Infrastructure

$\square$ Natural resources

$\square$ Cultural resources

$\square$ Economic resources

Figure 18. Desired hazard-asset overlays based on various hazards and asset combinations. 


\section{Examples of scale}

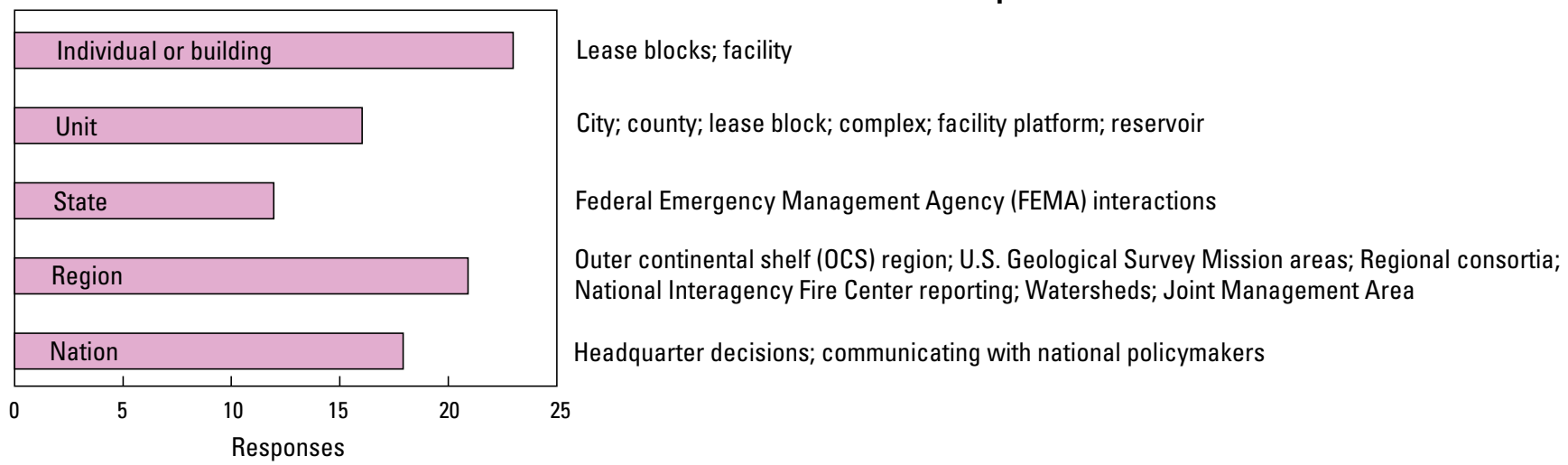

Figure 20. Desired scale of risk information and products that is most relevant to Department of the Interior (DOI) planning, including examples provided by participants.

\section{Frequency of Relevant Risk Information}

One element of an effective use case is capturing the frequency at which users need information. The current (2018-2019) SHIRA effort is focused on the development of one-time, risk-assessment products to inform DOI OEM strategic planning. However, from the broader perspective of DOI risk-management planning, workshop participants were asked to provide insight on the frequency with which they may want to access risk products or tools for their own planning efforts. Thirty-two workshop participants were asked to identify how often they would like to access risk information. Daily and annual updates were the most common responses, followed by monthly and semi-annually, and then weekly (fig. 21).

Participants provided comments on specific frequencies for which risk information would be relevant, including daily use for event response, weekly and monthly use for budgeting and resource allocation, and semi-annually and annually for continuity of operations (COOP) planning (fig. 21). A common refrain during table and group discussions was "I want it when I want it," reflecting an interest in information when conditions have changed, such as an imminent threat, a catastrophic event, asset information has been updated, or in response to a shortfuse data call. A number of workshop participants noted that the frequency with which they would use SHIRA-related products would depend on the frequency with which the data supporting these products were updated. If the data were updated more frequently, participants' use of these products would also be more frequent. For example, if information were only available semi-annually or annually, one workshop participant noted that $\mathrm{s} /$ he would use it solely for strategic planning purposes. However, if data were available on a monthly or more frequent basis, this participant said that $\mathrm{s} /$ he would use it for tactical purposes and facility management.

\section{Examples of frequency requests}

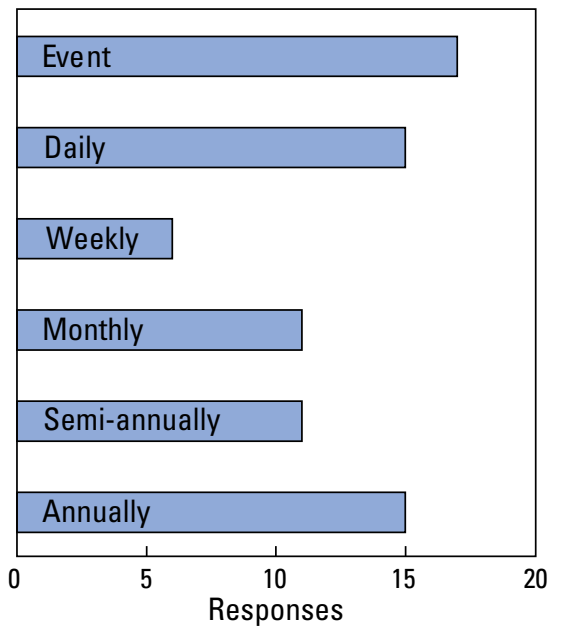

"I want it when I want it"

Event response; site analysis

Resource allocation every two weeks

Monthly stats for Director; plans/trends; budgeting; planning based on weather

Regional environmental impact statements; COOP reviews; quarterly financial reports

Annual strategic plans; continuity of operations (COOP) planning for facilities and staff

Figure 21. Desired frequency of risk information and products that is most relevant to Department of the Interior (DOI) planning, including examples provided by participants. 


\section{Format and Delivery of Information}

Information is only useful if people can access it and understand it in ways that are relevant to them. Given the wide array of interested bureaus and offices, the SHIRA Project will need to present information in multiple ways, such as tabular data, heat maps, bar charts, and infographics (fig. 22). It will also be looking into different ways to provide access to the information, such as the addition of hazard-exposure attributes to existing assets (for example, a facilities layer), new geospatial layers (for example, heat maps for assets or hazard exposure), or new interactive data applications.

Thirty-eight workshop participants were asked via an openended question on how they would prefer to see and receive risk information and products. Responses included comments on preferred formats and attributes, as well as hand-drawn sketches of potential visualizations and data-delivery methods. A dominant theme in responses was a desire for the ability to customize information (fig. 23), including:

- By scale (for example, local site-level assessments to national indicators);

\section{Site specific assessments}

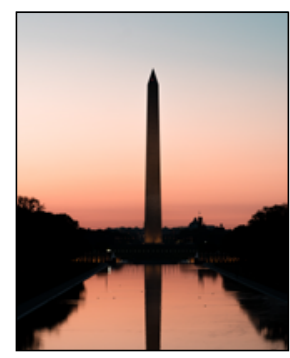

Hazard exposure information attached to existing data, including:

- Facilities

- Personnel locations

- Infrastructure

- Habitats

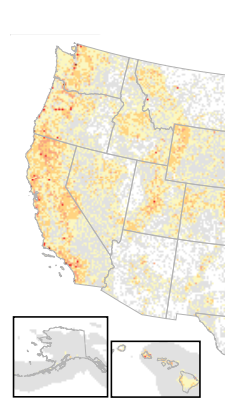

\section{Heat maps}

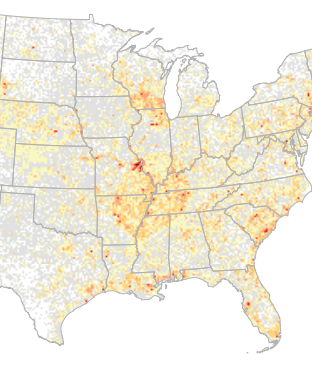

Number of

"high" hazards

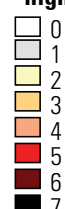

Bar charts

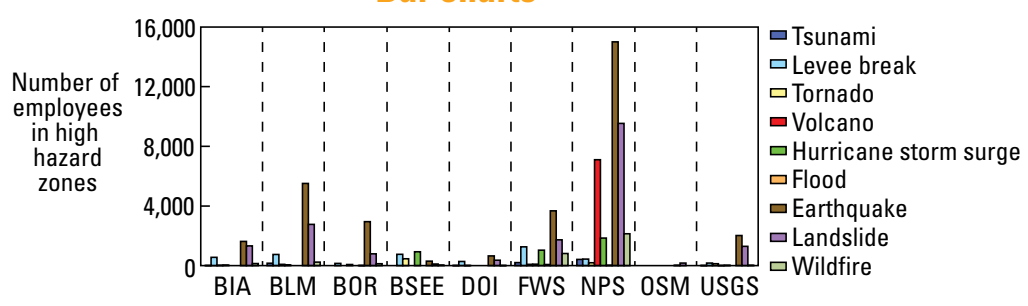

- By time period (for example, historic, current, or projected threats; annual versus seasonal perspectives);

- By hazard threshold (for example, hurricane storm surge hazard zones differentiated by storm category);

- By geography (for example, selected regions or watersheds); and

- By overlay interest (for example, user-driven combinations of land boundaries, hazard, and asset).

During the group discussion, participants continued to emphasize an interest in customizable information by hazard type, area and asset of interest, and spatial and temporal scale. The interest in customizable information was rooted in participants wanting the ability to set thresholds or minimal acceptable levels for implementing mitigation for plausible threats or initiating responses in the event of an actual incident. The earlier example of snowfall accumulation differences across the country represents one way to tailor risk information to the needs of regional managers who would like the ability to set the threat level for a specific hazard.

\section{Interactive data applications}

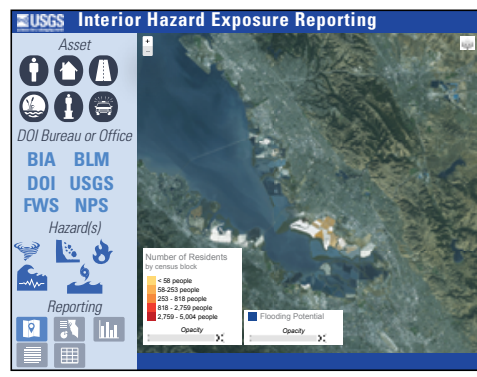

$$
\begin{aligned}
& \text { — Maps } \\
& \text { — Infographics } \\
& \text { — Comparative charts } \\
& \text { — Individual charts } \\
& \text { — Tables } \\
& \text { — Ability to see } \\
& \quad \text { data for a specific } \\
& \text { unit, location, or bureau }
\end{aligned}
$$

\section{Infographics}
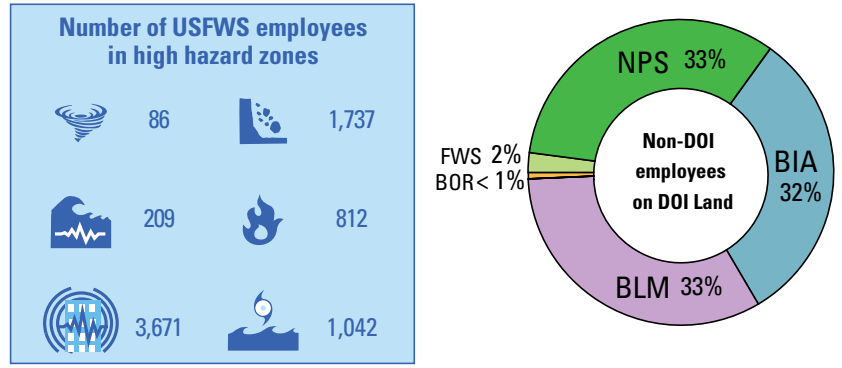

Tabular data

\begin{tabular}{c|c|rrrrrrr|}
\multicolumn{1}{c}{} & \multicolumn{2}{c}{ E0 Landslide } & Fire & Levee Torn & Tsu & Vol \\
\cline { 2 - 9 } & BIA & 1,629 & 1,321 & 140 & 563 & 21 & 4 & 31 \\
Number of & BLM & 5,508 & 2,771 & 236 & 746 & 90 & 159 & 49 \\
employees & BOR & 2,947 & 793 & 130 & 155 & & & 78 \\
in high & BSEE & 297 & 114 & 30 & 757 & 460 & & \\
hazard & DOI & 656 & 370 & 5 & 279 & 11 & 3 & \\
zones & FWS & 3,671 & 1,737 & 812 & 1,261 & 86 & 209 & 98 \\
& NPS & 15,007 & 9,541 & 2,138 & 443 & 190 & 415 & 7,102 \\
& OSM & 29 & 176 & & & & & \\
& USGS & 2,016 & 1,289 & 19 & 174 & 128 & 8 & 14 \\
\cline { 2 - 8 }
\end{tabular}

Figure 22. Examples of approaches to visualize and share risk information (showing only hypothetical examples). 


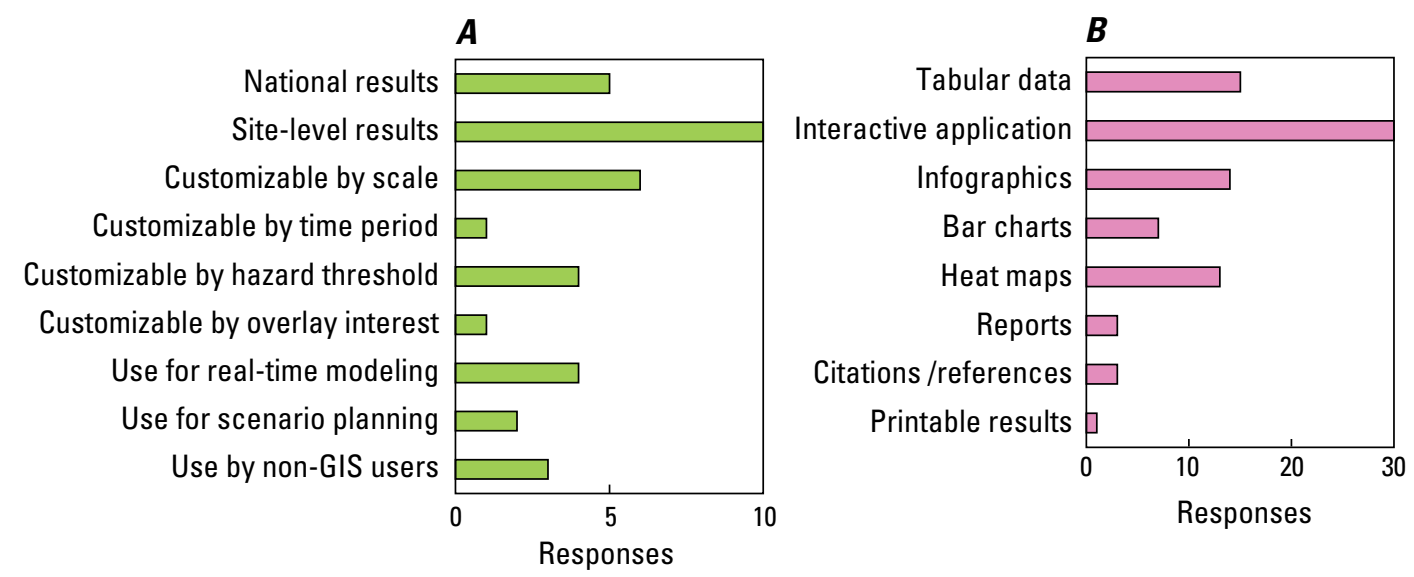

Figure 23. Desired characteristics of information and product delivery in terms of $(A)$ features and $(B)$ format.

A related characteristic of customizable information was participants' interest in access to raw hazard and asset data from the current risk assessment in some sort of data clearinghouse. This clearinghouse would ideally include (1) information on the source and timeliness of authoritative data, (2) user session memories, and (3) an alert function to let users know when data highlighted as relevant to a user is updated. Data access and customizable information were also discussed in the context of using data for developing realistic exercise scenarios and in realtime operational models. The ability to use information gathered for the SHIRA Project for real-time operational use is possible but is beyond the current focus on strategic planning. Additional resources would be required to expand this effort into real-time operational use and to maintain such a platform.

Interest in customizable information was also emphasized when participants were asked about preferred formats for results (fig. 23B). An interactive application was the most common response, followed by tabular data, infographic, and heat maps. Although not as common as other responses, several workshop participants expressed interest in the ability to develop reports and other printable products from the results. During the group discussion, participants emphasized simple and easy-to-digest visualizations and products that provide customizable information (fig. 24). These topics are being explored in a complementary USGS effort that is leveraging the data collection and partnership development of the SHIRA Project to create modular web services, analytical workflows, and visualization packages that can be relevant to a broad array of USGS efforts.

\section{Suggested Next Steps}

In addition to input provided during the workshop exercises, participants were given three specific opportunities to provide their thoughts on short-term project priorities (before the end of Fiscal Year 2018) and long-term goals for the SHIRA Project. The first opportunity was by writing comments on a poster hung up for the workshop duration, referred to as the "parking lot." The second opportunity was a session at the end of the workshop in which participants were asked to submit as many ideas as they would like on short-term priorities and longterm goals. The third opportunity was by providing comments in a workshop evaluation form.

The most common response for short-term priorities, long-term goals, and general project thoughts was that the SHIRA Project should continue its efforts to identify, compile, organize, and develop authoritative hazard and asset data (fig. 25). Echoing results from other exercises, workshop participants expressed a great amount of interest in having an authoritative and accessible database. Such a database would support not only the immediate OEM-USGS collaboration but also provide a foundation for other risk-related assessments that individual bureaus and offices may wish to complete. A related desire of the group was the creation and maintenance of a risk community of practice among DOI researchers and managers. Comments during group discussion included thoughts about the governance of such a group, as well as the creation of an advisory working group comprised of representatives from various DOI Bureaus and offices that could continue to inform OEM and the USGS of data, analytics, and visualization needs across the Department.

\section{Summary}

The SHIRA February 2018 workshop was envisioned as the beginning of a long-term conversation among DOI Bureaus and Offices about threats to DOI assets, lands, and resources. The workshop was designed to gather input on not only desired datasets and risk products for the FY18-19 effort, but also to collect insights on more long-term engagement. Overall, workshop participants saw considerable value in risk-related information for a wide array of DOI strategic planning efforts, including emergency management, law enforcement, and the management of facilities and natural resources. Participants noted that risk information supports not only internal planning efforts but also for communication with other Federal agencies, local to state governments, nonprofit organizations, and the public. 


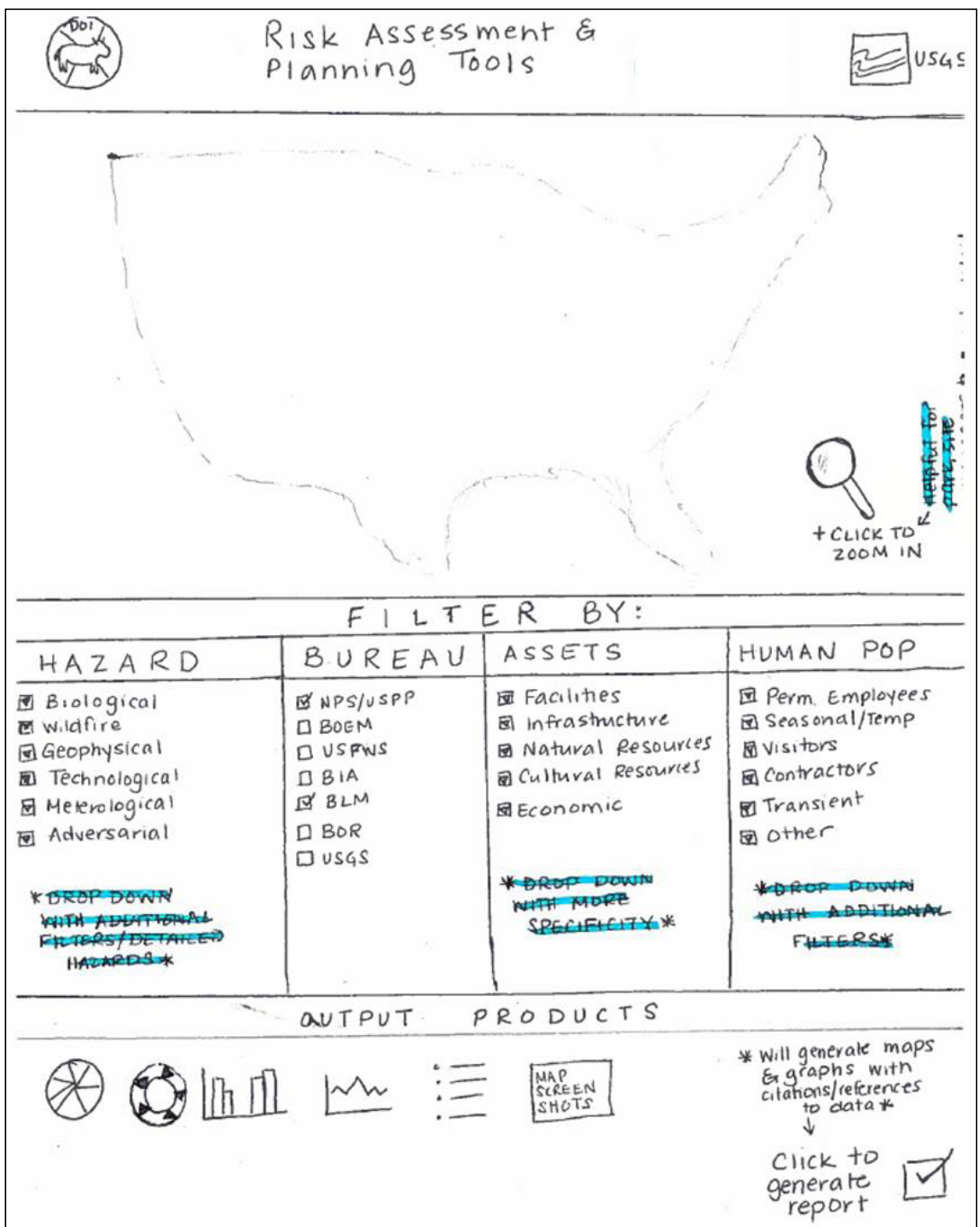

Figure 24. An example of a hand-drawn sketch by a workshop participant of a potential data dashboard for providing customizable risk information.

Continue data triage, management, and accessible repository Create community of practice and/or advisory working group Finetune scope of effort and identify users Demonstrate capabilities Various new hazard zones Use for operational response

Acquire various asset data Use for mitigation and recovery Create open source software repository Consider legal context Use for conservation planning Use for scenarios Connect to existing strategic plans

Develop self-improving tool

Develop smart-phone app

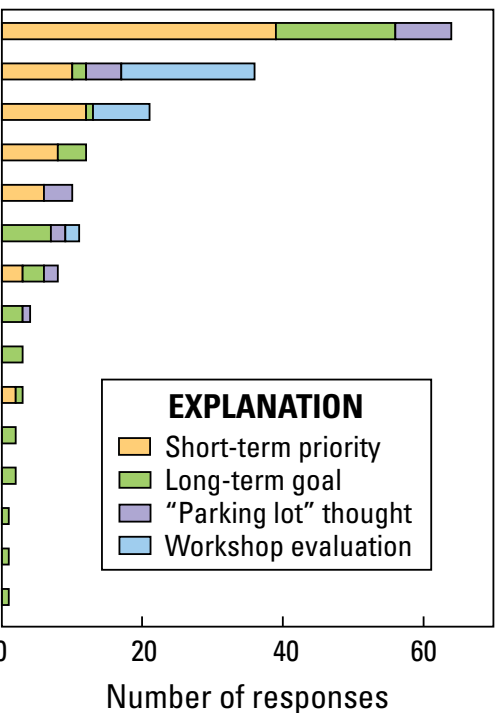

Figure 25. Responses on short-term priorities, long-term goals, and general project thoughts. 
There was considerable interest in authoritative risk information that is customizable by spatial scale (for example, local site-level assessments to national indicators), time period (for example, historic, current, or projected threats; annual versus seasonal perspectives), various hazard thresholds, and user-driven combinations of land boundaries, hazard, and asset. Participants desired risk information that characterized the hazard exposure of individual assets and resources, but also on cascading and systemic impacts. Interest in risk information included not only the analytical products but also the underlying hazard and asset data that could be accessed via a data clearinghouse. A data "wish list" was created based on participant input, including recommended data with identified points of contact and requested data for the SHIRA Project team to further investigate. There was also interest in additional data discovery related to hazards, including: (1) the potential use of historical occurrences, current status maps, short-term forecasts, and emerging projections, (2) differentiation of sub-hazards with distinct impact profiles (for example, lahar and ash for volcanic hazards), and (3) the full expression of hazard classes in mapped zones (instead of just high hazard zones). Given that several hazards lack mapped zones, participants were receptive towards and provided input on potential hazard categories, sub-categories, and attributes for a relative threat matrix to compare hazards instead.

In addition to providing input on short-term deliverables of the SHIRA Project (fig. 26), workshop participants noted several long-term goals to characterize DOI risks, including:

- Creating and maintaining a Department-wide community of practice to foster Bureau-wide engagement in risk analysis;
- Investing in long-term sustained efforts past the SHIRA Project to characterize and communicate DOI risks;

- Maintaining communication with other Federal agencies to leverage expertise, data, tools, and products; and

- Exploring tactical and real-time applications that build on the SHIRA Project investments in data compilation.

The February 2018 workshop and planning efforts that preceded it allowed for initial progress on several of these long-term goals, but their ultimate success will require sustained leadership, continued engagement, and dedicated resources (fig. 26). For example, the workshop laid the groundwork for a Department-wide community of practice that could expand its membership with more engagement of DOI Bureaus and Offices, and the SHIRA Project is compiling a large quantity geospatial data on hazards and assets of DOI concern that could serve as the basis for a data clearinghouse. However, hazards and assets are not static concepts and resources will be required to maintain and expand the database. An accessible data clearinghouse is not achievable within the current scope of the project and its future success would require collaboration and buy-in across the Department, as well as dedicated funding and resources to develop and maintain it. Communication with other agencies has already begun as part of the SHIRA effort, including meetings with the USFS and FEMA to discuss mutual risk interests. The project team intends to continue interagency discussions as risk information is produced.

There was considerable interest in the use of data compiled in the SHIRA Project for tactical and real-time applications, as well as for automatic scenario development for exercises. Similar to the data clearinghouse concept, such

\section{Desired activities}

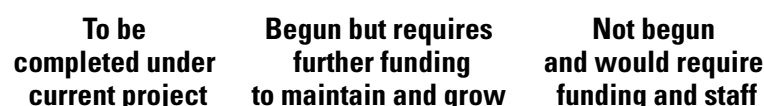

current project to maintain and grow funding and staff

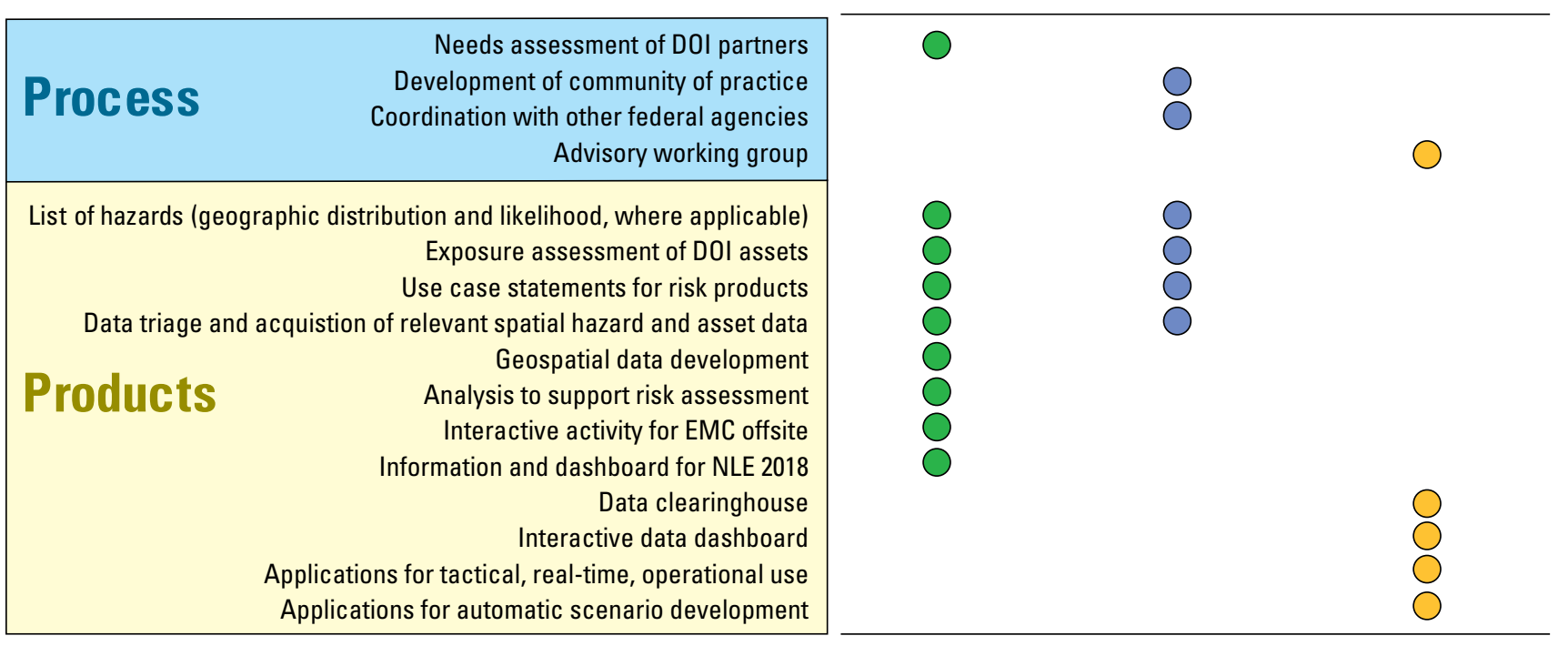

Figure 26. Overview of SHIRA-related processes and products desired by workshop participants. 
a deliverable is not achievable within the current project but is possible in subsequent years with dedicated funds and resources (fig. 26). To demonstrate the utility of the SHIRA collaboration, hazard-exposure data for DOI facilities and employees were generated to support the Department's engagement in the May 2018 National Level Exercise (NLE). If the products prove useful for the NLE, additional opportunities could be identified for expanding SHIRA capabilities to include tactical/response efforts in the future with additional funding.

In summary, the workshop met its stated goals of understanding how strategic risk information is used at the DOI, understanding the types and formats of useful data/information, determining desired data products, and collecting ideas for future project directions. The input provided by the workshop participants have not only informed the products to be delivered for the current SHIRA project, but have also demonstrated broad interest in risk analysis across the Department, which may lead to additional collaborations and opportunities.

\section{Acknowledgments}

The SHIRA Project and related workshop summarized in this report are supported by funds provided by the Department of Interior Office of Emergency Management. We thank the USGS Natural Hazards Mission Area for providing administrative support for project management. We also thank Peggy Gardiner, Aimee Cooper, Elizabeth Wasserman, and Bill Lukas of the USGS for providing logistical and facilitation support at the workshop and in workshop planning efforts. Any use of trade, product, or firm names is for descriptive purposes only and does not imply endorsement by the US Government.

\section{References Cited}

Cutter, S.L., 1996, Societal Vulnerability to Environmental Hazards: International Social Science Journal, v. 47, no. 4, p. 525-536.

Department of the Interior (DOI) Office of Emergency Management (OEM), 2014, All-Hazards Baseline Operational Plan: The Department of the Interior, Accessed April 3, 2018, at: https:/www.doi.gov/sites/doi.gov/files/migrated/ emergency/upload/DOI-Baseline-Ops-Plan-Final-Signed4JUNE14.pdf.
Department of the Interior (DOI), 2012, Part 900-Emergency Management Program in: Series 41-Emergency Management, Departmental Manual, Accessed April 3, 2018, at: https://www. doi.gov/sites/doi.gov/files/elips/documents/Chapter $\% 20 \% 20$ 1 \%20POLICY\%2C\%20FUNCTIONS\%2C\%20AND\%20 RESPONSIBILITIES.doc.

Dow, K., 1992, Exploring differences in our common future(s); the meaning of vulnerability to global environmental change: Geoforum, v. 23, p. 417-436.

Federal Emergency Management Agency (FEMA), 2017, Federal Continuity Directive 1 (FCD 1): Washington, D.C., U.S. Government Printing Office, $64 \mathrm{p}$.

Gergely, K.J., and McKerrow, A., 2016, PAD-US-National inventory of protected areas (ver. 1.1, August 2016): U.S. Geological Survey Fact Sheet 2013-3086, 2 p.

Hewitt, K. 1997, Regions of Risk: A geographical introduction to disaster. New York: Addison Wesley Longman, 389 p.

Holmes, R.R., Jr., Jones, L.M., Eidenshink, J.C., Godt, J.W., Kirby, S.H., Love, J.J., Neal, C.A., Plant, N.G., Plunkett, M.L., Weaver, C.S., Wein, A., and Perry, S.C., 2013, U.S. Geological Survey natural hazards science strategy - Promoting the safety, security, and economic well-being of the Nation: U.S. Geological Survey Circular 1383-F, 79 p.

Intergovernmental Panel on Climate Change, 2014, Annex II; Glossary [Mach, K.J., S. Planton and C. von Stechow (eds.)], in Pachauri, R.K. and Meyer, L.A., eds., Climate Change 2014 Synthesis Report. Contribution of Working Groups I, II and III to the Fifth Assessment Report of the Intergovernmental Panel on Climate Change: IPCC, Geneva, Switzerland, p. 117-130.

Ludwig, K.A., Ramsey, D.W., Wood, N.J., Pennaz, A.B., Godt, J.W., Plant, N.G., Luco, N., Koenig, T.A., Hudnut, K.W., Davis, D.K., and Bright, P.R., 2018, Science for a risky world -A U.S. Geological Survey plan for risk research and applications: U.S. Geological Survey Circular 1444, 57 p.

Turner, B.L., Kasperson, R.E., Matson, P.A., McCarthy, J.L.,Corell, R.W., Christensen, L., Eckley, N., Kasperson, J.X., Luers, A., Martello, M.L., Polsky, C., Pulsipher, A., and Schiller, A., 2003, A framework for vulnerability analysis in sustainability science: Proceedings of the National Academy of Sciences, v. 100 , no. 14 , p. 8074-8079.

Weichselgartner, J. 2001, Disaster mitigation - the concept of vulnerability revisited: Disaster Prevention and Management; An International Journal, v. 10, no. 2, p. 85 - 95. 


\section{Glossary and Appendixes}




\section{Glossary}

Key terms in risk reduction have a range of definitions and consensus on each term is difficult given the spectrum of disciplines and practitioners using them. Below are working definitions taken from the literature (for example, Dow, 1992; Cutter, 1996; Hewitt, 1997; Weichselgartner, 2001; Turner and others, 2003; Holmes and others, 2013; Intergovernmental Panel on Climate Change, 2014).

Adaptive capacity The ability of systems, institutions, humans, and other organisms to adjust to potential damage, to take advantage of opportunities, or to respond to imminent threats.

Exposure The presence of people, livelihoods, species or ecosystems, environmental functions, services, and resources, infrastructure, or economic, social, or cultural assets in places that could be adversely affected. Exposure is related to hazard proximity and the environmental characteristics of the hazard, such as speed of onset, duration, and pre-onset cues.

Hazard A dangerous process, phenomenon, substance, activity or condition that may cause loss of life, injury or other health impacts, property damage, loss of livelihoods and services, social and economic disruption, or environmental damage. Acute or suddenonset hazards are those events that occur on timescales of minutes to days (for example, earthquake, flood, tsunami, wildfire, hurricane), whereas chronic hazards occur on longer timescales (for example, seasonal coastal erosion, drought, sea level rise).

Loss Death, injury, and health impacts to human populations; damage to or destruction of homes, businesses, livestock, critical infrastructure, and other property; disruption or cessation of livelihoods, cultural or social structures, activities, and customs, economic exchange, and critical services; and environmental degradation.

Mitigation Action, including education, which eliminates or reduces the potential effects of a hazard.
Resilience The ability to prepare for and adapt to changing conditions and to withstand and recover rapidly from disruptions. Resilience includes the ability to withstand and recover from deliberate attacks, accidents, or naturally occurring threats or incidents.

Risk The potential for consequences where something of value is at stake and where the outcome is uncertain, recognizing the diversity of values. Risk sometimes is represented quantitatively as probability of occurrence of hazardous events multiplied by the impacts if these events occur. Risk results from the interaction of hazards and a vulnerable asset or system. Risk can be further broken down into various sub-categories, including the following three entries.

Risk assessment The qualitative and (or) quantitative scientific estimation of risks.

Risk management Plans, actions, or policies to reduce the likelihood and (or) consequences of risks or to respond to consequences.

Risk perception The subjective judgment that people make about the characteristics and severity of a risk.

Sensitivity The personal or situational conditions that influence the degree to which an individual, group, system, or species may be affected by a hazard. For example, demography and socioeconomic status have been found to influence the sensitivity of an individual to hazards, whereas construction type and practices influence the sensitivity of buildings to certain hazards (for example, earthquakes and floods).

Vulnerability The combination of physical, social, cultural, economic, historical, and political components that influence the degree to which an individual, community, or system is susceptible to damaging effects of a hazard. Although definitions and applications of the term 'vulnerability' vary, common elements within the hazards literature include concepts of exposure, sensitivity, and adaptive capacity. 


\section{Appendix 1. List of Participants}

\begin{tabular}{|c|c|c|}
\hline Bureau & Name (Last, First) & Area of expertise \\
\hline BIA & Caesar, Sid & Emergency management \\
\hline $\mathrm{BIO}$ & Quinlan, Martin & Business integration \\
\hline BLM & VanderWeele, Dave & Emergency management \\
\hline BOEM & Dufore, Chris & Oil spills \\
\hline BSEE & Miller, Dana & Emergency management \\
\hline BSEE & Pittman, Mike & Regulatory programs \\
\hline IBC & Beall, Jim & Enterprise management \\
\hline NPS & Haas, James & Oil spills \\
\hline NPS & Hower, Andrew & Emergency management \\
\hline NPS & Said, Maria & Public health \\
\hline $\mathrm{OCIO}$ & Ah Tong, Kayloni & Data management \\
\hline $\mathrm{OCIO}$ & Sauve, Peter & Telecommunications \\
\hline OEM & Juskie, John & Emergency management \\
\hline OEM & Marineau, Jason & Emergency management \\
\hline OEPC & Nelson, John & Natural and cultural resources \\
\hline OEPC & Scida, Pasquale & Oil spills \\
\hline OLES & Benavidez, A.J. (Ben) & Law enforcement \\
\hline OLES & Shea, Candace & Emergency management \\
\hline OWF & West, Jeremy & Wildland fire \\
\hline PAM & Lasser, Craig & Property and acquisitions management \\
\hline PPA & Miller, Ann & Economics \\
\hline PPA & Simon, Ben & Economics \\
\hline Reclamation & Sorensen, Grant & Emergency management \\
\hline USFWS & Covington, Scott & Refuge management \\
\hline USFWS & Gibbs, Samantha & Wildlife health \\
\hline USGS & Bright, Patti & Environmental health \\
\hline USGS & Bristol, Sky & Biogeography \\
\hline USGS & Clampitt, Lance & Data management \\
\hline USGS & Ewert, John & Volcano hazards \\
\hline USGS & Godt, Jonathan & Landslide hazards \\
\hline USGS & Henry, Kevin & Geospatial analysis \\
\hline USGS & Hopkins, Camille & Ecosystems (wildlife heath/disease) \\
\hline USGS & Hsu, Leslie & Data management \\
\hline USGS & Jaiswal, Kishor & Earthquake hazards \\
\hline USGS & Jones, Jeanne & Geospatial analysis \\
\hline USGS & Kolar, Cindy & Invasive species \\
\hline USGS & Leith, Bill & Earthquake hazards \\
\hline USGS & Ludwig, Kris & Natural hazards \\
\hline USGS & Mason, Robert & Floods \\
\hline USGS & Pennaz, Alice & Natural hazards \\
\hline USGS & Pindilli, Emily & Economics \\
\hline USGS & Schnebele, Emily & Energy and minerals \\
\hline USGS & Shelton, Greg & Emergency Management \\
\hline USGS & Steblein, Paul & Wildfire \\
\hline USGS & Stockdon, Hilary & Coastal hazards \\
\hline USGS & Wasserman, Elizabeth & Workshop note-taking \\
\hline USGS & Wood, Nathan & Societal vulnerability \\
\hline USPP & Libby, Michael & Emergency management \\
\hline
\end{tabular}




\section{Appendix 2. Workshop Agenda}

\section{Day 1 (Tuesday Feb. 27, 2018)}

8:30 Welcome and opening remarks (Harry Humbert, DOI Deputy Assistant Secretary, Public Safety, Resource Protection and Emergency Services)

8:45 USGS opening remarks (Bill Leith, Senior Science Advisor for Earthquake and Geologic Hazards)

9:00 Introductions, housekeeping, agenda overview (Peggy Gardiner, USGS)

9:15 Project expectations and workshop goals (Kris Ludwig and Alice Pennaz, USGS)

9:30 SE-EMC List of Hazards (Jason Marineau, Preparedness Coordination Program Manager, DOI OEM)

9:45 Framework of hazard, exposure, and risk (Nathan Wood, USGS)

10:15 Break

10:45 Making decisions and using information: Use-case activity \#1

12:15 Check-in/preview of afternoon

12:30 Lunch

1:30 Identifying your audience: Use-case activity \#2

2:00 Information you use and how you use it

3:00 Break

3:30 Hazard characteristics and considerations

4:45 Check-out/Final thoughts and Day 1 conclusions

5:00 Adjourn

\section{Day 2 (Wednesday Feb. 28, 2018)}

8:30 Check-in, overview of day's agenda and goals

9:00 Data wish list revisited

10:00 Break

10:30 Format and delivery part I: What should the suite of products look like?

11:30 Format and delivery part II: Gallery walk and discussion

12:30 Lunch

1:30 Information delivery: frequency, geographic scale, and comparisons

2:30 Project next steps, ideas for future directions

3:30 Closing Remarks

4:00 Adjourn 


\section{Appendix 3. Workshop Materials}

The following section summarizes the desired outcomes, approaches, and developed materials for each interactive workshop session.

\section{Session 1- "Making Decisions and Using Information: Use-Case Activity \#1"}

Desired outcome-Descriptions of risk-based decisions that DOI Bureaus make and the data needed to make decisions

Approach — A worksheet was filled out individually, followed by table and group discussions.

Materials - Worksheet included three questions:

- My bureau makes the following 3 decisions/plans to manage and protect this resource/asset of concern* [assigned to each table].

- What kind of information is being used to make these decisions/plans?

- I wish someone would provide me with to better inform these decision/planning processes.

\section{Session 2- "Identifying Your Audience: Use-Case Activity \#2"}

Desired outcome-Improved understanding of audiences for DOI risk information

Approach - Individuals wrote a current or potential audience (for example, DOI organization, external group) on a single post-it note. Post-it notes were then grouped on easel paper for a specific table. Table and group discussions followed.

Materials - Post-note notes, easel paper

\section{Session 3- "Information You Use and How You Use It"}

Desired outcome - Identification of different types of specific information that might be useful to DOI Bureaus; list of needs for data types that have not already been considered

Approach - A worksheet was filled out individually, followed by table and group discussions

Materials-Worksheet shown here

\section{Session 4- "Hazard Characteristics and Considerations"}

Desired outcome - Working understanding of desired geographic and temporal scales of data as well as useful combinations of hazards and assets

Approach - Three worksheets were filled out individually, followed by table and group discussions

Materials-Three worksheets shown here

\section{Session 5— "Data Wishlist Revisited: Gallery Walk"}

Desired outcome - Clarified desired data types; list of point of contacts for future data collection; identification of data of particular interest across bureaus

Approach - Participants were asked to walk around the room to look at data wish list items. Participants were asked to (i) identify (if possible) using a post-it a point-of-contact name for providing relevant data, (ii) add a post-it note describing extra information they may want on different types of data, and (iii) place a blue sticker next to any data that they want to prioritize.

Materials - 1) Lists of data wish lists from the use case exercise on Day 1,2) blue sticker dots, and 3) post-its

\section{Session 6— "Format and Delivery: What Should the Suite of Products Look Like"}

Desired outcome-Working list of desired formats for final products; list of desired features and characteristics for final suite of products

Approach-As individuals, each person drew what useful information would look like that they would use for strategic decision making. Participants were encouraged to consider different formats that would be useful to them (for example, spreadsheet, bar graphs, interactive dashboard, maps, etc.). Participants could also list or describe if they preferred writing over drawing. Individuals then walked around the room to take notes on attributes or formats they liked. Table and group discussions were then done.

Materials-1) Blank paper, 2) pens 


\section{Session 7- “Information Delivery: Frequency, Geographic Scale, and Comparisons"}

Desired outcome - Information on how frequently bureaus want to receive risk information, and over what geographic scale; information on whether or not comparisons of risk information across bureaus is important

Approach - Worksheet followed by table and group discussions.

Materials-Worksheet

\section{Session 8- "Information Delivery: Frequency, Geographic Scale, and Comparisons"}

Desired outcome-List of recommended next steps

Approach-Participants wrote down 1-2 recommended next steps on a white index card and 1-2 recommended moonshots or long-term ideas on a blue index card.

Materials-Index cards

\section{WORKSHEET - DOI Assets of Concern}

Bureau/Office:

A DOI "asset of concern" is something that is critical to DOl's ability to carry out its mission. We have defined 6 categories with examples of things that could be included

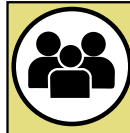
Human life safety

DOl employees and contractors, non-DOl employees (for example, concessionaires) and visitors on DOI lands, students (for example, tribal schools), and residents on DOl lands

Minimum data provided: Number of various populations in hazard zones Potential additional details: Demographics of residents (for example, age, ethnicity) Visitor types (recreationists, nonrecreationists)

Would additional data details be useful (yes/no)?

If yes, how would you use this information?

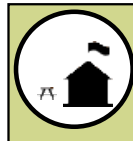

\section{Facilities}

DOI buildings including offices, visitor centers, campgrounds, law enforcement offices, emergency services (for example, firehouses), schools, and medical services

Minimum data provided: Number of buildings in hazard zones

Potential additional details: Type of building (for example, school level, type of emergency services facility, type of DOI building)

Would additional data details be useful (yes/no)?

If yes, how would you use this information?

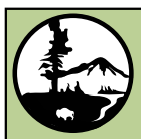

\section{Natural resources}

Critical habitats, wildlife ranges, threatened and endangered species, overall amount of land

Minimum data provided: Number/area of resources in hazard zones Potential additional details: Habitat by species, amount of land by agency/state

Would additional data details be useful (yes/no)?

If yes, how would you use this information?
-- Circle the category or examples that would be most useful to you -- Let us know which additional data details would be useful to you -- Share with us how this information would be useful in your planning

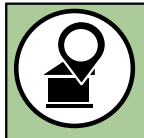

\section{Cultural resources}

Historic places, archaeological sites, registered landmarks and monuments, and areas of significant cultural meaning (for example, homelands or burial sites)

Minimum data provided: Number of sites in hazard zones

Potential additional details: Type of historic place (for example, districts, sites, buildings, structures, and objects), sensitive vs. nonsensitive

Would additional data details be useful (yes/no)?

If yes, how would you use this information?

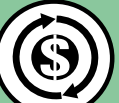

\section{Economic resources}

Mining operations, mineral resources, oil and gas production areas, rangeland, visitor revenue

Minimum data provided: Revenue sources and estimated value in hazard zones Potential additional details: Visitor spending by unit, types of natural resource revenue, type of mines)

Would additional data details be useful (yes/no)?

If yes, how would you use this information?

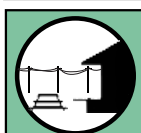
Infrastructure

DOI and non-DOl infrastructure on DOI land including roads, rail, bridges, pipelines, trails, electrical and telecommunications infrastructure, and dams

Minimum data provided: Number/length of infrastructure in hazard zones Potential additional details: Type/class of infrastructure (for example, road class, type of telecommunication tower, type of pipeline)

Would additional data details be useful (yes/no)?

If yes, how would you use this information?

Figure 3.1 Worksheet for "Information You Use and How You Use It" session, which was used to identify assets of concern. 
Bureau/Office:

\section{WORKSHEET - Relative hazard and impact characteristics}

A goal of the Department of the Interior (DOI) risk project is to determine the greatest threats to DOI land, people, infrastructure, and resources. However, hazards are not assessed in a consistent way, making it difficult to quantitatively compare them. This activity is designed to provide guidance on how to compare all hazards. Here we compare hazards based on characteristics that influence an organization's ability to mitigate, prepare for, respond to, and recover from an extreme event. The end product is a relative threat matrix.

\section{INSTRUCTIONS}

-- We have listed several characteristics here as examples, including potential ranges of values.

-- Please circle the characteristics that are most relevant to you and " $X$ " out those that are not relevant in your risk planning.

-- Please add other characteristics for the project to consider

\section{Hazard and impact characteristics}

- How fast it may happen (speed of onset)

- How long it may last (duration)

- How much warning before impacts (warning)

- How big impacts may be (severity)

- How often it happens (frequency)

- How big of an area that it impacts (scale)

Year or more
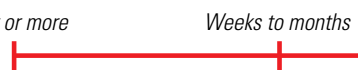

Year or more

Weeks to months

Weeks to months

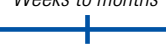

able loss

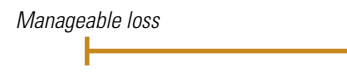

Only geologic evidence

Once in a generation

Building or individual
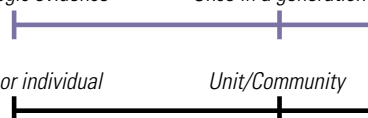

$\mathbf{P}^{-1}$

Days

Hours

Days Hours Minutes

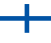

Hours

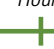

Minutes
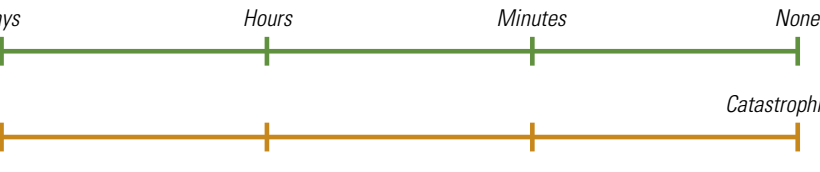

Decadal

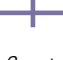

Low dread

dread

Contro

Easy to predict

r

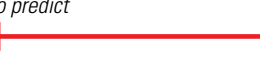

- How well it can be predicted (predictability)

\section{Are there other relevant characteristics to consider?}

Figure 3.2 Worksheet \#1 for "Hazard Characteristics and Considerations" session, which was used to identify which hazard characteristics were of most interest by participants. 
Bureau/Office:

\section{WORKSHEET - Mapping hazards in DOI risk products}

Some of the hazards in the Senior Executive Emergency Management Council (SE-EMC) hazard list can be mapped and subsequently used in the GIS-based exposure analysis. During the proof-of-concept analysis, we focused just on "high" hazard zones in long-term assessments. However, hazard zones can be mapped in different ways. The following questions are designed to provide guidance on how to further map hazards.

1) Hazards can be characterterized using a range, instead of just present vs. not present. Would additional hazard classes be helpful? Examples include:

\section{Helpful? (yes/no) Additional comments?}

-- Earthquake (high, medium, low)

-- Wildfire (very high, high, medium, low, very low)

-- Hurricane storm surge (categories 1 - 5 storms)

-- Tornado (EF scale 0 - 5)

-- Other hazards?

2) Hazards can be characterterized using historical databases. Would these be useful?

-- Chronic wasting disease

Helpful? (yes/no) Additional comments?

-- Tornado

-- High wind

-- Extreme heat

-- Snow

-- Oil spills and other technological failures

-- Other hazards?

3) Some hazard types are made up of several hazards. Would it be useful to separate them? Examples include:

$\begin{array}{llll} & \text { Sub-class } & \text { Helpful? (yes/no) Additional comments? } \\ \text {-- Volcano } & \text { Ash vs. lahar } & - \\ \text {-- Toxic/flammable materials } & \text { Material type } & - \\ \text {-- Other hazard types? } & - & -\end{array}$

Figure 3.3 Worksheet \#2 for "Hazard Characteristics and Considerations" session, which was used to identify how to best map certain hazards that may have ranges in magnitude, may be only characterized using historical data, or may be composed of many sub-classes. 


\section{WORKSHEET - Hazards-Assets Overlay Table}

There are many possible GIS combinations of hazard and asset data, but not all of them may be useful in your planning.

Please provide us with input on the kind of hazard-asset exposure analysis that would best serve your needs.

\section{INSTRUCTIONS}

- Write an "X" in each cell to indicate the overlays that you would be interested in seeing in terms of hazards (rows) and Department of the Interior (DOI) assets (columns)

- Identify any combinations of multiple datasets (for example, earthquake + pipeline + critical habitat) by circling the data and/or connecting with lines

\begin{tabular}{|c|c|c|c|c|c|c|}
\hline Biological hazards (human health) & $\begin{array}{c}\text { Human } \\
\text { populations }\end{array}$ & Facilities & Infrastructure & $\begin{array}{l}\text { Natural } \\
\text { resources }\end{array}$ & $\begin{array}{l}\text { Cultural } \\
\text { resources }\end{array}$ & $\begin{array}{l}\text { Economic } \\
\text { resources }\end{array}$ \\
\hline \multirow{4}{*}{$\begin{array}{r}\text { Zoonotic disease } \\
\text { Toxicological disease } \\
\text { Human pandemic outbreak } \\
\text { Harmful algal blooms }\end{array}$} & & & & & & \\
\hline & & & & & & \\
\hline & & & & & & \\
\hline & & & & & & \\
\hline
\end{tabular}

\section{Biological hazards (ecosystem health)}

\begin{tabular}{|r|l|l|l|l|l|l|}
\hline Infestations & & & & & \\
Wildlife disease outbreak \\
\cline { 2 - 7 } & Water quality & & & & & \\
\cline { 2 - 7 } & & & & & & \\
\hline
\end{tabular}

\section{Wildfire hazards}

\section{Meteorological hazards}

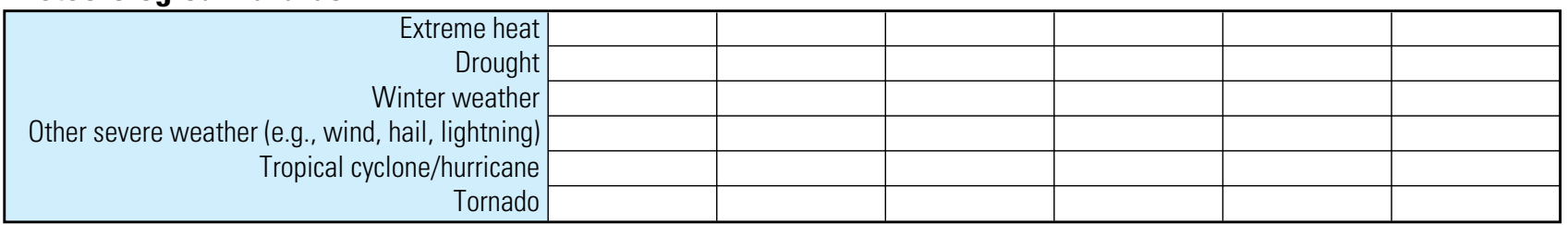

\section{Geophysical hazards}

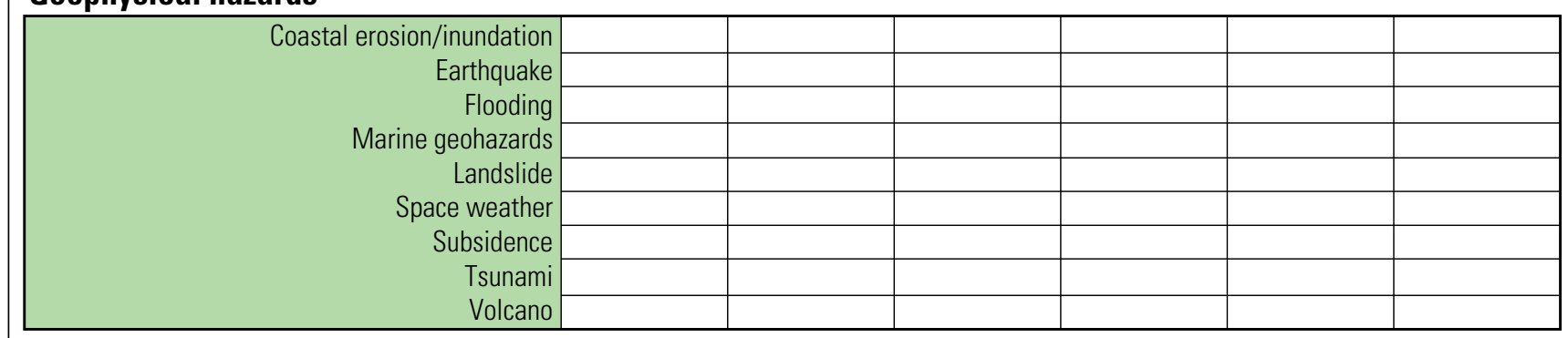

Technological hazards

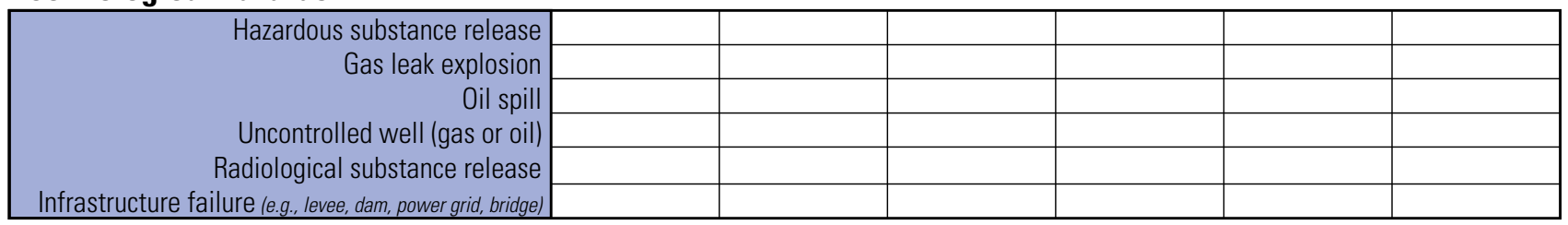

\section{Adversarial hazards}

\begin{tabular}{|r|l|l|l|l|l|}
\hline Armed assault / active shooter & & & & & \\
Cyber attack (data) & & & & & \\
\cline { 2 - 6 } Cyber attack (physical infrastructure) & & & & & \\
Significant law enforcement incident & & & & & \\
Cross border illegal activity & & & & & \\
\cline { 2 - 6 } Terrorism (various types) & & & & & \\
\hline
\end{tabular}

Figure 3.4. Worksheet \#3 for "Hazard Characteristics and Considerations" session, which was used to identify which combinations of hazards and assets would be of greater interest to participants. 
Bureau/Office:

\section{WORKSHEET - Understanding frequency and scale of products}

Important factors in an effective risk assessment are the frequency and spatial scale that planners want information. Please provide us with your thoughts on how often and at what scale would be most useful to you.

\section{Frequency of information}

In general, how often do you want to receive risk-related information? (circle your response)

1 - daily

2 - weekly

3 - monthly

4 - semiannually

5 - annually

You may want different information at different frequencies. If this is the case, please provide 1-2 specific examples of what you would need at various frequencies.

\section{Scale of information}

\section{What scale of information is most useful to you? (circle your response)}

1 - Individual building or asset

2 - Unit (for example, National Park Service park, Fish and Wildlife Service refuge)

3 - State

4 - Region

5 - National

You may want different information at different frequencies. If this is the case, please provide 1-2 specific examples of what you would need at different scales.

We can provide metrics that compare different bureau/office exposure to hazard at different scales.

For example, we can show at a national level how many Bureau of Land Management v.s. Bureau of Indian Affairs assets are in a specific hazard zone.

\section{Would this information be useful? (yes/no)}

If yes, how would you use this information? (please explain)

Figure 3.5 Worksheet for "Information Delivery: Frequency, Geographic Scale, and Comparisons" session, which was used to identify how frequently and over what geographic scale that participants want to receive risk information. 


\section{Appendix 4. Examples of Use Case Statements}

Input from workshop participants will be used to create a series of use case statements to help guide data discovery, hazard-exposure analysis, and potential visualization approaches. For those not familiar with use cases, we provide here examples for various DOI Bureaus or Offices based on workshop participant input. These examples are illustrative and not exhaustive of all possible use cases for a certain audience (for example, emergency managers versus resource managers) or for a specific DOI Bureau or Office.

\section{Bureau of Indian Affairs (BIA)}

Use Case-Assess the level of risk from hazards for individual BIA-managed facilities to inform continuity of operations (COOP) plans

Categories—Assessment, mitigation planning

Assets—Facilities, cultural resources

Hazards—Natural, human-induced

Data (Used)—DOI facilities; DOI lands data (BIA managed)

Data (Desired) - DOI facility data with specific hazard exposure information in attributes; overlays of individual hazard layers

Inputs — Web application; web services

Outputs—Maps, tabular data, infographics

Scale —-Individual building or asset

Frequency-Annual

\section{Bureau of Land Management (BLM)}

Use Case-Assess risks to wildlife and habitat (for example, sage grouse, grazing, timber) from hazards that include wildfires, floods, and mudslides in order to determine the severity of impacts for mitigation planning

Categories-Assessment, mitigation planning

Assets-Natural resources

Hazards-Natural, human-induced

Data (Used) —DOI Lands Data (BLM owned); drought monitor data; fire hazards data; lease sales; conservation plans
Data (Desired) — hazard maps overlaying BLM land; land use maps (grazing, oil and gas, timber, conservation zones, threatened species areas)

Inputs - Web application; web services

Outputs - Maps, tabular data, infographics, bar charts

Scale-Variable

Frequency-Variable

\section{Bureau of Ocean Energy Management (BOEM)}

Use Case-Determine the hazard-related risks to assets located within a specific region in order to update environmental impact statements for lease sale documents

Categories-Assessment, mitigation planning

Assets-Economic resources, infrastructure, natural resources

Hazards-Natural, human-induced

Data (Used)—Unknown

Data (Desired)—DOI Lands Data; hazard maps overlaying the region

Inputs—Web application; web services

Outputs—Maps, tabular data

Scale-Regional

Frequency-Semiannual

\section{Bureau of Safety and Environmental Enforcement (BSEE)}

Use Case-Assess the risks to employees and infrastructure for a particular hazard for continuity of operations (COOP) plan review and scenario exercise set up/ planning

Categories-Assessment, mitigation planning

Assets - Human life safety, infrastructure, facilities

Hazards-Natural, human-induced

Data (Used)—Unknown 
Data (Desired) - DOI Lands Data; hazard maps overlaying DOI land and facilities; DOI personnel (location); DOI facilities; infrastructure (for example, pipelines, ports, airports, rail lines, cell towers, substations, power lines) maps

Inputs - Web application; web services

Outputs-Maps, tabular data, bar charts

Scale — Variable (regional to site specific)

Frequency-Semiannual

\section{U.S. Fish and Wildlife Service (FWS)}

Use Case-Determine health threats to park visitors and concessionaires in order to (1) target educations about a threat for prevention (website, factsheets, newsletter, consultation), and (2) take action such as integrated mosquito management, vaccination, isolation, quarantine, and appropriate medical care

Categories - Assessment, mitigation planning, monitoring, event response

Assets-Human life safety

Hazards-Natural, human-induced

Data (Used)_-Scientific literature; public health literature; postings from the CDC and state and local health departments

Data (Desired)_-Data on the presence of (1) ticks and what diseases they carry, (2) disease-carrying mosquitoes, (3) pathogens in soil and water, and (4) avian influenzas; data on the risks to people from ticks, mosquitoes, etc.; historical occurrence data on these hazards

Inputs_-Web application; web services

Outputs - Maps, tabular data, bar charts, infographics

Scale-Individual unit

Frequency-Variable

\section{Office of the Chief Information Officer (OCIO)}

Use Case-Assess telecommunications infrastructure exposure, risks, and vulnerabilities to hazards (physical and cyber-related) in order to determine the need to implement redundant connectivity telecommunications systems; monitor the allocation and utilization of other equipment such as electromagnetic spectrum systems, both owned and co-owned or co-operated with other agencies; develop mitigation plans to account for additional assets, mobile capabilities, and transportable resources needed to be deployed in response to hazard events

Categories_-Assessment, mitigation planning, monitoring, event response

Assets-Infrastructure

Hazards - Natural, human-induced

Data (Used) _ Cyber-specific event information; coverage maps (broadband, wireless, radio); telecommunication service providers (location and type); availability of resources; location of non-terrestrial (that is satellite) telecommunications resources

Data (Desired)_Extended real-time data (available resources, connectivity paths); telecommunications infrastructure (critical vs. non-critical, physical vs. cyber, DOI vs non-DOI dependent providers and transport

Inputs_-Web application; web services

Outputs-Maps, tabular data

Scale-Variable (national to site-specific)

Frequency_-Variable

\section{Office of Emergency Management (OEM)}

Use Case-Assess the likelihood of hazards occurring at DOI employee locations in order to (1) update the Personnel Accountability Plan, (2) determine what information, training, and equipment is needed to mitigate the impact of a disaster, (3) provide personnel disaster preparedness training to prepare DIO employees for hazard situations, and (4) create Post Disaster Support Plans to provide for the protection of employees after a disaster

Categories —-Assessment, mitigation planning

Assets-Human life safety

Hazards - Natural, human-induced

Data (Used)_-DOI Lands Data; DOI facilities data 
Data (Desired) _ DOI personnel data (locations); DOI facility data (locations) with employee population counts; data on types and relative risk of hazards at employee locations

Inputs - Web application; web services

Outputs-Maps, tabular data, infographics

Scale_-Individual asset, regional, national

Frequency-Semiannual/ annual

\section{Office of Law Enforcement and Security (OLES)}

Use Case-Assess factors critical to law enforcement administration and operations, including population demographics, geographic dispersion, and response times to aide in the development of guidelines, plans, and policies (for example, law enforcement annex, 'break glass' plans, use of force and equipment policies, occupant safety plans)

Categories - Assessment, mitigation planning, monitoring, event response

Assets-Human

Hazards-Natural, human-induced

Data (Used) — Bureau-level law enforcement staffing/geographic dispersion, and response times; population demographics

Data (Desired) — Resource distribution; local asset support (fire, EMS, SWAT, etc.); real-time staffing availability

Inputs - Web application; web services

Outputs-Maps, tabular data

Scale-Variable

Frequency-Variable

\section{Office of Wildland Fire (OWF)}

Use Case - Examine maps of invasive species, human population growth, beetle kill, and relative forest health overlaid with a wildland fire hazard potential map in order to see areas of greatest convergence for making decisions on the distribution of resources for wildland fire management
Categories - Assessment, mitigation planning

Assets-Natural resources, human life safety

Hazards - Wildfire

Data (Used)_-Wildland fire potential map

Data (Desired)_-DOI lands map with surrounding non-DOI land; invasive species maps; projected residential growth maps; beetle infestation maps; forest health indicators

Inputs-Web application; web services

Outputs-Maps, tabular data

Scale-Regional to site-specific

Frequency - Daily/weekly during fire season, monthly for budget planning; semiannual/annual for policy and planning (multi-year in order to see site specific trends)

\section{U.S. Geological Survey (USGS)—Use case \#1}

Use Case-Assess impact to critical habitats at risk stemming from a spread of environmental contaminants

Categories_-Assessment, mitigation planning

Assets-Natural

Hazards - Natural, human-induced

Data (Used)_PAD-US; DOI/USGS Active Directory; hazard-related datasets; current and historical point data (for example, sites, mines, etc.); communication with land managers familiar with species habitat in area of interest

Data (Desired) - Economic impact caused by the spread of invasive species; historical information on the occurrence and distribution of infectious diseases

Inputs — Web application; web services

Outputs-Maps, tabular data

Scale-Site-specific, local, regional

Frequency_Variable 


\section{U.S. Geological Survey (USGS)—Use case \#2}

Use Case-Assess inventory of minerals deemed critical to U.S. economy and/or national security in order to make recommendations to stock pile and acquire (for example, import) such minerals

Categories—Assessment, mitigation planning

Assets-Economic

Hazards-Natural, human-induced

Data (Used) — Production and consumption of minerals across the U.S.; Trade sources

Data (Desired) - Information on minerals at risk to natural hazards; overlays of mineral resources and hazards; utility and transportation networks; structural sensitivity of mining facilities to particular types of hazards (for example, earthquake, flood)

Inputs - Web application; web services

Outputs-Maps, tabular data

Scale-Variable

Frequency-Semiannual/annual

\section{U.S. Park Police (USPP)}

Use Case - Identify the locations of DOI personnel and assess risk from hazards for those locations in order to update park emergency operations / response plans and protect employees in National Parks

Categories-Assessment, mitigation planning, event response

Assets-Human life safety

Hazards-Natural, human-induced

Data (Used)—Unknown

Data (Desired) —DOI Lands Data (NPS owned); DOI personnel (locations); hazard maps

Inputs - Web application; web services

Outputs-Maps, tabular data

Scale —Individual facility / asset, unit level

Frequency-Annual 


\section{Appendix 5. Data Availability and Wish List}

Throughout the workshop, participants had various opportunities to identify data that they would like to see included in the SHIRA Project. Here we list data types that were identified during the workshop and in the SHIRA Project. Data are categorized as (1) acquired, meaning the SHIRA team has the data as of the workshop date, (2) available, meaning the SHIRA team knows of the data and may use if it is considered relevant by DOI Bureaus and Offices, (3) recommended, meaning data currently exist according to a workshop participant and a point of contact was provided, and (4) requested, meaning the data may or may not currently exist, but a workshop participant would like to see that data included if possible.

After the workshop, SHIRA team members will be exploring whether specific data exist and if they do, how feasible would they be to include in the hazard-exposure analysis. As one can see from this list, there is a considerable amount of data to be considered. Therefore, the SHIRA Project will be determining what data are available and can best inform strategic planning, as opposed to other data that either need additional development to be useful or are more relevant to short-term, operational uses. Data requiring additional development could be addressed in future years with additional resources.

\section{Hazard Types}

\section{Adversarial}

- Group includes - Armed assault or active shooter; cyber-attack (data); cyber-attack (physical infrastructure); law enforcement incident; cross border illegal activity; terrorism

- Acquired-None as of the workshop date

- Available-Unknown prior to workshop; "hazard zones" likely do not exist; data on historic occurrence may be only available data, although it may not exist in a central, accessible repository

- Recommended-None provided

- Requested-Historic database on civil unrest, crime data, and cyber attacks

\section{Biological (Human Health)}

- Group includes - Zoonotic disease; toxicological disease; human pandemic outbreak; harmful algal blooms

- Acquired-None as of the workshop date
- Available - Unknown prior to workshop

- Recommended-Disease outbreak events

- Requested-Accidents/injuries; agricultural contaminants; arthropod vectors (mosquitoes, etc.); at risk populations; food safety and security; human population growth; hunting and fishing zones; language barriers; mental health; offshore military and industrial waste areas; tetanus; vaccine preventable diseases; water borne disease

\section{Biological (Ecosystem Health)}

- Group includes - Infestations, invasive species, wildlife disease outbreak, water quality

- Acquired-Animal disease outbreak (Chronic wasting disease)

- Available - Regional fish barriers

- Recommended -Detections and forecasting data for invasive pathogens; soil characteristics map; ticks and mosquitoes

- Requested-Avian influenza in wild birds; cheatgrass; chronic wasting disease occurrence; disease transmission potential of invasive species; disease vector presence and absence data; economic impact of invasive species; environmental data for dates of wildlife disease (temperature and humidity); habitat suitability for disease vectors; historic occurrence of invasive species; migratory movements of wildlife; non-indigenous aquatic species database; ranges of disease vectors (mosquitos, whitefooted mouse); routine forest health; soil maps ( $\mathrm{pH}$, moisture) to determine pathogen persistence; soil maps, water maps, and characteristics which impact fate and effects of contaminants and pathogens; soil pathogens; threat prioritization for invasive species; vector borne disease maps; water data for areas of aquatic disease outbreak; Whitenose syndrome

\section{Geophysical}

- Group includes - Coastal erosion and inundation, earthquake, flooding, marine geohazards, landslide, space weather, subsidence, tsunami, volcano

- Acquired-Earthquake (RF8 map); flood (DFIRM, although little coverage on Federal lands); landslide (1-km national grid); tsunami (deterministic scenarios); volcano hazards (aggregate of summit buffers and lahar hazard zones where available) 
- Available - Unknown prior to workshop; require additional clarification of what is meant by "marine geohazards" and "subsidence" relative to other hazards already being mapped

- Recommended-Coastal erosion and over wash on beaches during storms; coastal erosion due to sea level rise; eddy currents and loop currents; long-term shoreline change

- Requested-Flood inundation; geomagnetic storms; probabilistic flood map; sea ice; storm surge; submarine landslides; tsunami inundation; wind damage

\section{Meteorological}

- Group includes - Drought, extreme heat, severe weather (wind, hail), winter weather (snow, ice storm, extreme cold), tornado, tropical cyclone/hurricane

- Acquired-Hurricane storm surge (Sea, Lake and Overland Surges from Hurricanes (SLOSH) model outputs by category); tornado (historic occurrence)

- Available - Short-term forecasts for drought, extreme heat, severe weather (wind, hail), winter weather (snow, ice storm, extreme cold)

- Recommended - None provided, other than input that short-term forecasts are useful

- Requested-Climate trends; climate trends to regional level RCPs; drought/extreme heat

\section{Technological}

- Group includes - Hazardous substance release, gas leak explosion, oil spill, uncontrolled well, radiological substance release, infrastructure failure

- Acquired-Levee failure; chemical substance spills

- Available - Contaminated sites

- Recommended-Consequence relationships to mining variables ( 8 versus 24 hour shifts, number of people); current contaminants; downstream effects (contaminants, abandoned mine lands); legacy contaminants

- Requested-Abandoned mines; chemical plants; current contaminants; downstream effects; equipment component failure data (well control, safety, and pollution prevention); landfills; legacy contaminants; oil-spill contingency areas; superfund sites, continued testing of wildlife on-site

\section{Wildland Fire}

- Acquired -Wildfire Hazard Potential (WHP)

- Available - Burnable areas - DOI Lands (contiguous United States); current fires; post-fire debris flow

- Recommended-Wildfire, DOI predictive services, USDA fire and aviation management

- Requested - Area actively burning; past fire debris flow and flooding; smoke, ash, blown particles

\section{Assets}

\section{Cultural Resources}

- Acquired-Historic places (National Register of Historic Places)

- Available - Museums historical sites similar institutions

- Recommended-Resources and Under Sea Threats (RUST) database for offshore archeological resources; tribes

- Requested-Areas of significant cultural meaning; BIA database of expertise contacts; BIA tribe list; historic places, national registry of historic places; museum curators; Native American burial grounds; Presidentially declared disasters; State listed historic properties; traditional, cultural properties; vetted subject matter expert's sensitive to need for discretion

\section{Economic Resources}

- Acquired-Mining operations;

- Available - Oil refineries; natural gas processing plant; biodiesel plants; ethanol plants; natural gas storage facilities; strategic and petroleum reserves

- Recommended - Customer (Federal agency) location and revenue; economic value of grazing, timber, recreation (NPS/FWS but also BLM, Reclamation); hydropower and irrigation; mine locations; visitor expenditures; visitor spending

- Requested-Barrier equipment component failure and reliability information; communities dependent on DOI managed lands for local economy; downstream facilities and energy availability; economic value of infrastructure system output; fishing industry zones; grazing land; mineral mining facilities; mineral resources commodities and locations; mining 
operations; mining platform infrastructure; mitigation costs; natural resource revenue; oil and gas production, including data and locations on oil refineries, natural gas processing plans, biodiesel plants, and ethanol plants; value of wildlife resources; visitor revenue

\section{Facilities}

- Acquired-Facilities and Building Management System (FBMS) database; emergency services; DOI law enforcement; DOI buildings; schools

- Available -FWS campgrounds; nursing residential care facilities; pharmacies; USGS flood gauges; weather radar stations; prisons and detention centers; ammunition storage; hazardous materials storage; warehouse explosives; solid waste landfill facilities

- Recommended-DOI facilities function and priority; DOI laboratories; national

- Requested-Ammunition; campgrounds; capacity; concentrated feeding operations; elevation; emergency services; explosives; functionality and capabilities; hazardous materials; housing critical communications nodes; law enforcement; nursing residential care facilities; offices (DOI owned); offshore platforms; pharmacies; pit toilets; prioritization for deferred maintenance; prioritization (for example for recovery); prisons and detention centers; replacement costs for facilities; schools; Snow Telemetry (SNOTEL) Network sites; structural sensitivity; underground storage tanks; visitor centers; waste disposal (solid waste landfill); wastewater treatment

\section{Infrastructure}

- Acquired-Bureau of Reclamation projects; electric power transmission lines; oil and gas pipelines; railroads; streets; communications towers

- Available - Aircraft landing facilities; airstrips; National Bridge Inventory bridges; dam lines; dams; electric substations; data centers; internet service providers; levee lines; major us port facilities; power plants; drinking water sources; wastewater treatment plants; drinking water treatment plants

- Recommended - Cell coverage (overall); communication towers (radio); data centers; domesticated animal facilities (poultry operations, aquaculture facilities); emergency / non-emergency calls; internet service providers; national map infrastructure data; Outer Continental Shelf production data (oil and gas); solar and wind energy zones (areas with highest potential); telecom redundancy (network)

- Requested - Aircraft landing facilities and airstrips; boat ramps; bridges; critical versus non-critical infrastructure; communication towers; compressor stations; critical communication nodes (coordination centers, mission critical facilities); dam lines and locations; data centers; data for energy and injury comparison, import export international production, facility pipelines short of the tie-in to dot pipelines; designated energy corridors; hatcheries; domesticated animal facilities; Department of Transportation (DOT) Pipeline and Hazardous Materials Safety Administration pipeline database; drinking water sources; drinking water treatment plants; fiber; fire resistance for facilities; infrastructure redundancy; internet service providers; irrigation; levees; location of intakes/outfalls; locations of staged satellite phones, spare antennas; low density communications areas (under-served); major U.S. port facilities; maps of reliable cell coverage within DOI lands; national bridge inventory; non-DOI dependency for telecommunications (provider and transport); offshore oil and gas platforms; parking lots; pipelines; potential pipelines or electric transmissions lines; power plants; productions facilities (platform longevity); proposed oil transportation; railroads; redundant telecommunications connectivity; renewable energy plan projections; renewable energy project proposals or potential state-designated areas; road network; substations; tank batteries; transmission lines; transportations plans; upstream effects - dams, chemical plants; Bureau of Reclamation projects

\section{Natural Resources}

- Acquired - Critical habitats (FWS); PAD-US

- Available-The Nature Conservancy (TNC) ecoregional priorities; Cumulative Habitat Condition Indices for National Fish Habitat Action Plan; stream connectivity; Refuge and Hatchery assets; Refuge and Hatchery cadastral boundaries; National Wildlife Refuge System general information; Marine Protected Parcels; National Wetland Inventory; Coastal Barrier Resources System; Migratory Bird Conservation Fund; fuel treatments; Greater Sage Grouse (GRSG) habitat; species watch list for DOI lands; Endangered Species Act grants; aquifers; sage grouse occupied range

- Recommended-Environmental sensitivity index maps (coastal resources); National Gap Analysis Project (GAP) data; GAP data adjusted to climate trends; GAP species habitat maps; migratory wildlife spatiotemporal 
data; National Wetlands Inventory; National Terrestrial Ecosystems

- Requested-Aquatic species habitat (shell and finfish); aquifers; areas subject to closure to protect wildlife; bottom depth high resolution; caves and caverns; coastal barrier resources system; coral reefs; critical ecosystems dependencies; critical habitats; culverts, small dams, fish passage impediments; cumulative habitat condition indices; domesticated herd locations; eagle nest/roost sites; elevation data in coastal regions; Endangered Species Act grants; fuel treatments; grazing leases and wildlife ranges; Greater Sage Grouse habitat; habitat type; high resolution bathymetry in Gulf of Mexico; land cover/ canopy cover; land use at the wildlife urban interface; local agency management plans; marine protected parcels; migration patterns of wildlife, stop-over sites, corridors; migratory bird conservation fund sites; migratory bird flyways; National Wildlife Refuge system general information; NOAA environmental sensitivity index map; NOAA trajectory modeling surface; land subsurface critical resource; BOEM probability trajectory data and modeling; non Threatened and Endangered species data; National Water Information System (NWIS) data; on-farm lagoons; potential for recovery; protected areas database; range of threatened or endangered species; range of threatened or endangered species due to climate change; refuge and hatchery boundaries and assets; sage grouse occupied range; sensitive wetlands; species watch list for DOI Lands; stream connectivity; timber leases; TNC ecoregional priorities; type of jurisdiction: exclusive, concurrent, proprietary; USGS stream gauges; zoning areas around refuge

\section{Populations}

- Acquired-DOI employees (DOI Active Directory and FBMS data); Non-DOI employees (private and public) on Federal land (infogroup); residents; NPS Visitors

- Available - Students Bureau of Indian Education (BIE) schools and FBMS data)

- Recommended - Incidents, human life, injuries; traffic counts

- Requested -Alternative work sites; backcountry permit information; budget projections (5yr, 10yr); building control systems; calls to information lines/non-emergency numbers; cellular service stats; communications interoperability and National Interoperability Field Operations Guide data; concessionaires; emergency call data; employee housing data; employees, DOI Active Directory; employees, non-DOI public employees on DOI land; employees, private sector on DOI land; Federal jurisdiction descriptions for inter-related activities, (for example BSEE, BOEM, USCG, EPA, NOAA, FWS, NMFG); fee collection stations; fire protection assessments; healthcare statistics/ems reporting; historical mitigation; human populations surrounding DOI land; intelligence information; law enforcement data; mobility issues; park concessionaire data; pet ownership near refuges; population trends for human and wildlife (urbanization); regulated operators, drillers, support contractors; residential data; safety reporting; seasonal employees; special events (planned and unplanned); spill responders; staffing data; students, BIE schools, owned and funded; students, other schools on DOI land; trail counts; travel data; visitor contacts; visitors; volunteers in parks. 


\section{Appendix 6. Potential Hazard Categories in Relative Threat Matrix}

\section{(4) HAZARDS}

Event Characteristics

Frequency

Likelihood

Speed of onset

Duration

Temporal predictability

Spatial predictability

Ability to map zones

Cascading hazards

\section{Not happened yet \\ Unknown or low $(<5 \%)$ \\ $>$ Year \\ $>$ Year \\ Predictable \\ National \\ No ability \\ Isolated event}

Range of Attributes

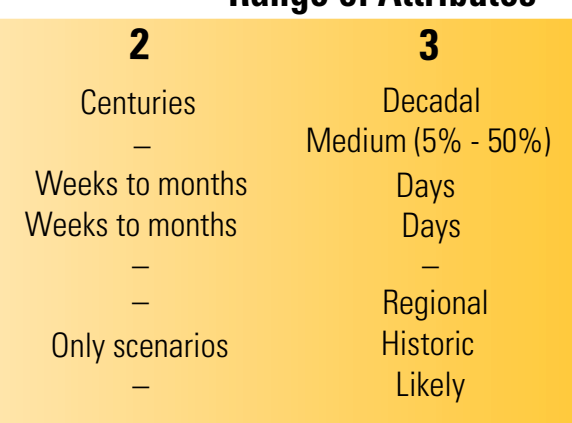

$\begin{array}{cc}\mathbf{4} & \mathbf{5} \\ \text { Annual } & >\text { Monthly } \\ - & \text { High (>50\%) } \\ \text { Hours } & \text { Instantaneous } \\ \text { Hours } & \text { Minutes } \\ - & \text { Unpredictable } \\ - & \text { Local } \\ \text { Short-term } & \text { Long-term } \\ - & \text { Highly likely }\end{array}$

\section{ACTIONS}

\section{Pre-Event}

Warning or detection ability Ability to mitigate losses

1
Year or more
Unrealistic

\section{Response}

Ability to control hazard

\begin{abstract}
Unrealistic
\end{abstract}

$$
<1 \text { day }
$$

\section{Range of Attributes}

$\begin{array}{cccc}\mathbf{2} & \mathbf{3} & \mathbf{4} & \mathbf{5} \\ \text { Weeks to months } & \text { Days } & \text { Hours } & \text { Minutes to none } \\ - & \text { Possible but high cost } & - & \text { Possible and low cost }\end{array}$

Days to weeks

Uncontrollable

\section{IMPACTS}

\section{Potential}

Scale of impact

Severity to humans

Severity to assets ${ }^{1}$

Dread

Cost

Impact to DOI mission

Benefits

Legal implications

Media exposure
$-$

$-$

\section{Range of Attributes}

\section{1}

Building or individual Unit or community

None

None

Low

$>\$ 0.1 \mathrm{M}$

No impact

Significant

None

No attention

\section{3}

County or watershed

Health effects

Minimal damage

$\$ 0.1 \mathrm{M}$ to $\$ 1 \mathrm{M}$

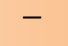

$-$

$-$

Local
Moderate damage

$\$ 1 \mathrm{M}$ to $100 \mathrm{M}$

Mission delayed

Some benefits

-

State

\section{4}

Regional

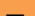

Major damage

\$100M to $\$ 1 \mathrm{~B}$

$-$

$-$

-

National

\section{5}

National

Death

Complete loss

High

$>\$ 1 \mathrm{~B}$

Mission ended

No benefits

Significant

International

Figure 6.1 Hazard categories for the Department of the Interior (DOI) in relative threat matrix. Workshop participants provided input on relevant categories for comparing all hazards. This figure includes a set of attributes for each category. It is illustrative and will evolve based on continuing discussions. Note: Severity to assets ${ }^{1}$ encompasses several elements, including facilities, infrastructure, cultural assets, ecosystems, and economic resources. Each element would be individually assessed with the same 1 to 5 attributes. 
Menlo Park Publishing Service Center, California

Manuscript approved February 12, 2019

Edited by Phil Frederick

Layout by Cory Hurd 


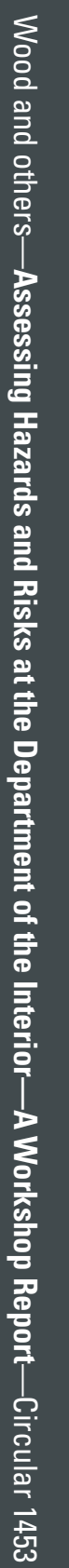

